Portland State University

PDXScholar

Spring 5-14-2015

\title{
Using Socratic Questioning as an Instructional Tool to Help High School Students at Grade Twelve Improve Their Perceptions of the Writing Process
}

Rana Houshmand

Portland State University

Follow this and additional works at: https://pdxscholar.library.pdx.edu/open_access_etds

Part of the Educational Methods Commons

Let us know how access to this document benefits you.

\section{Recommended Citation}

Houshmand, Rana, "Using Socratic Questioning as an Instructional Tool to Help High School Students at Grade Twelve Improve Their Perceptions of the Writing Process" (2015). Dissertations and Theses. Paper 2346.

https://doi.org/10.15760/etd.2343

This Dissertation is brought to you for free and open access. It has been accepted for inclusion in Dissertations and Theses by an authorized administrator of PDXScholar. For more information, please contact pdxscholar@pdx.edu. 
Using Socratic Questioning as an Instructional Tool to Help High School Students at Grade Twelve Improve Their Perceptions of the Writing Process

by

Rana Houshmand

A dissertation submitted in partial fulfillment of the requirements for the degree of

\author{
Doctor of Education \\ in \\ Educational Leadership: Curriculum and Instruction
}

Dissertation Committee:

Susan Lenski, Chair

Dannelle Stevens

Gayle Thieman

DeLys Ostlund

Portland State University 2015 
(C) 2015 Rana Houshmand 


\begin{abstract}
The purpose of this study was to determine whether Socratic questioning, an approach that builds critical thinking skills and fosters learning by constructing new knowledge, was an effective tool for improving student perceptions of the writing process. The main research question that was examined in this study was: How can Socratic questioning improve students' perceptions of writing and the writing process? Qualitative research methods were used as a framework for the design of this study as well as purposeful student sampling, triangulation of three data sources, and an extensive coding process Findings from the study support that Socratic questioning can positively impact students: the first major finding was that student perceptions of the writing process improved, and the second major finding was that student perceptions of their own identities as writers improved as well. After the study, students found that being an effective writer was possible and that evaluation of one's writing was a vital part of becoming a better writer. Most importantly, after participating in this study, students believed themselves to be writers.
\end{abstract}




\section{Acknowledgements}

Being a doctoral candidate has been one of the greatest challenges in my life. It has shifted the paradigm by which I understand the world and changed who I am as a teacher, a wife, a friend, a daughter, a sister, and most importantly a writer. Doctoral candidacy is paradoxical in nature; it forces you to come to grips with opposing realities that simultaneously exist. On any given day you might find a doctoral candidate jumping for joy, pumping her fist in the air, and feeling a sense of great accomplishment, and a few moments later she might be huddled in a corner and losing the battle in which sanity is replaced by the depths of despair. While teaching a full load of high school students and navigating the waters of being a researcher, I felt confusion, loneliness, uncertainty, paralysis, bravery, pride, accomplishment, and ambition all at the same time. There are many people who helped me through that series of emotions, guided me to create something special and valuable, shared in my experience, and need to be recognized.

To my amazing committee, thank you from the bottom of my heart for all the time and energy spent reading, discussing, and helping me design a study that was meaningful. Dr. Susan Lenski, there is nothing like the appreciation a doctoral student has for her doctoral advisor. Thank you for your guidance. In a world with many paths, you helped me find one that worked for me. Thank you for your flexibility and acknowledging how tough this can be while teaching full time. Thank you for calling on me when I had fallen off the radar. Thank you for reminding me that I wasn't alone. Thank you for accepting my desire to send you eight emails in a row at 4:00 am on a Monday morning. Thank you 
for always, always, always responding and giving me feedback so quickly. Thank you for believing in my study, and most importantly, thank you for believing in me.

Dr. Dannelle Stevens, thank you for reminding me how much I love to write and that words are powerful. The suggestions you gave at the start of my study proved to be the most valuable and the most critical. Your insight made my study something I enjoyed completing and something I could be proud of. Dr. Gayle Thieman, from my GTEP advisor to my committee member, you pushed me to be the educator that I am today. Your voice has always been in the back of my mind, pushing me to be better. On the brink of quitting the GTEP program, you looked me in the eye and told me I was meant to be a teacher. This job is tougher than I ever imagined. Not a day goes by in my classroom that I don't transport back to that moment in your office. Dr. Ostlund, thank you so much for joining the committee with open eyes and open arms. You brought a unique perspective to my study that would not have been there without you, and most importantly, your edits and suggestions brought much needed decisiveness to my writing and my research questions.

Grant, thank you for believing in me when I didn't even believe in myself. This dissertation is as much yours as it is mine. In fact, you might have read my writing more than I did. You pushed me, supported me, helped me, and read to me. You were my editor, my IT support, and my hero. I still don’t know when to use "of," "in," or "on,” and the only reason my computer is still intact is because you wouldn't let me take it out back and give it a piece of my mind! Thank you for reminding me that I could do this on a daily and sometimes even hourly basis. Thank you for putting my fears, meltdowns, 
and complaints ahead of your own thoughts and your own projects. If I didn't have you in my life, I would not have finished this. You are my greatest friend and the most loving husband.

Dad, 6 years ago, I called and asked if you thought I could hack a doctoral program. You laughed a little, but only because you thought it was a crazy question to even ask. You said, as you always said when I was growing up, "You can do anything you want to do. You can be anything you want to be." Even as an adult, those words were what I needed to hear to believe that I could do this. I did it, Dad! Thank you for reminding me that I had it in me! Mom, thank you for the prayers, the love, and the motivation that only a mother can give. I don't think anyone is as excited as you are about this. You might even be more excited than me! You have always put us girls before yourself, and there are not enough thank yous in the world to tell you how grateful I am that I had a mother like you.

Adrian, you are amazing, thank you!! Elias, Shelbi, Sunshine, Phil, Nicole, Kasey, and Stacy, thank you for covering my classes, putting up with my tears, keeping me sane in this crazy place, and reminding me there was more to life than the pages of my dissertation and the walls of my classroom. Thank you for reading my work, editing my work, and believing that my work was worth something. Liz, Amy, Jill, and Kathy, thank you for knowing without a doubt that I could do this. Whenever I would waiver, and other people asked why I was putting myself through all of this, you were there to snap me out of it! You never let me down! Thank you for almost a decade of love, 
playfulness, kindness, encouragement, and understanding. Raha and Saba, you keep me grounded in who I was, who I am, and who I want to be. I love you both so much!

A special thank you to Netflix for the many hours spent marathoning, spicy green Thai curry, walks at sunrise, pajama pants, random chocolate offerings, and petite Syrah for allowing me to forget and reminding me to breathe.

Last but not least, my most deep appreciation goes to my students who taught me to love life and laugh at myself. You allowed me rummage around in your thoughts, regrets, goals, and fears. Every day you walked into my room, you made me want to be a better teacher. Every time you allowed me to sit and talk with you, you reminded me how raw, real, and forgiving humans can be. Thank you for inspiring me to dig deeper into the world of discussion, collaboration, and creation. You are what all this was for. 
Table of Contents

Page

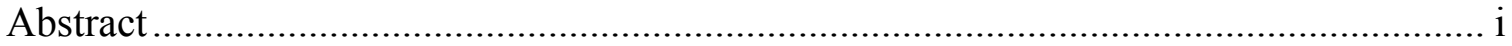

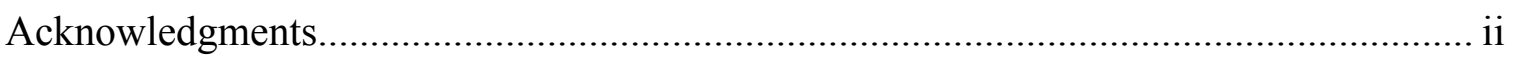

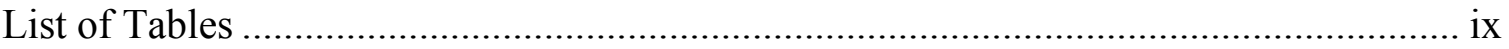

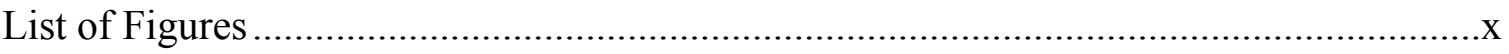

Chapter

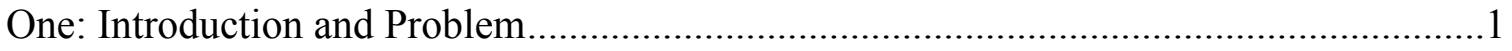

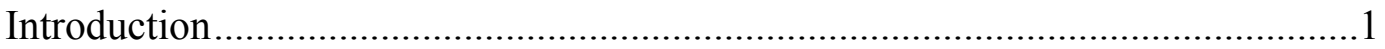

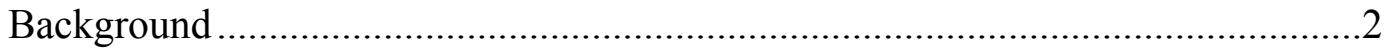

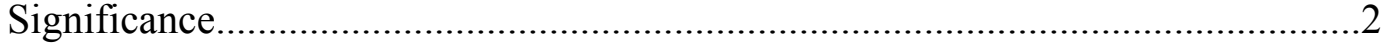

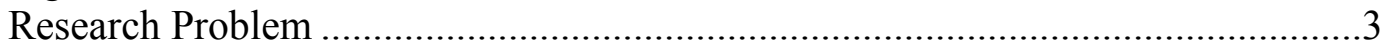

Problem Statement ....................................................................................

Research Questions and Methodology........................................................6

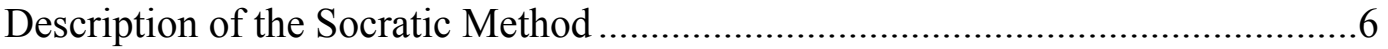

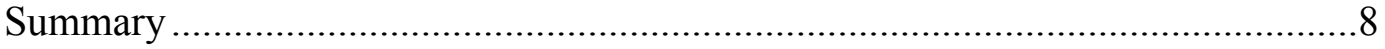

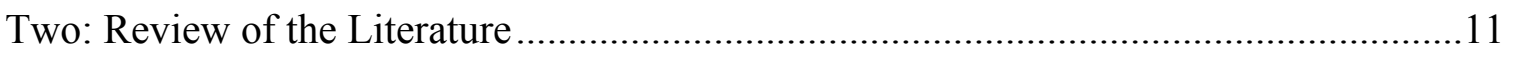

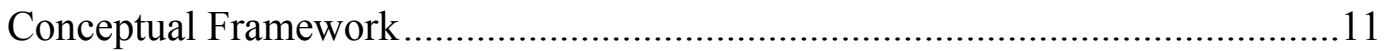

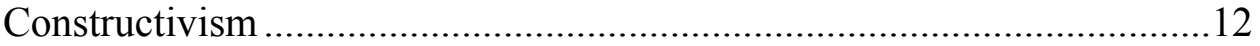

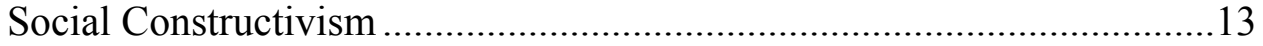

Social Constructivism and the Socratic Method......................................16

Introduction for Literature Review .............................................................. 18

Importance of Questioning in the Classroom ......................................19

Types of Classroom Questioning ........................................................20

Influence of Socrates and the Socratic Method on Questioning...............22

Socratic Method and Research.............................................................23

Importance and the Problem of Defining Critical Thinking .....................25

Power and Poverty in the Classroom ...............................................27

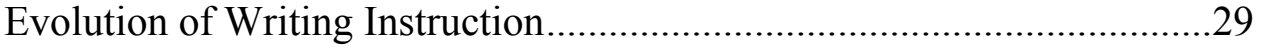

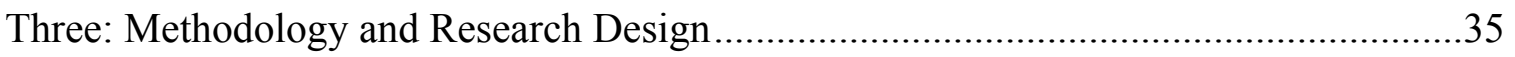

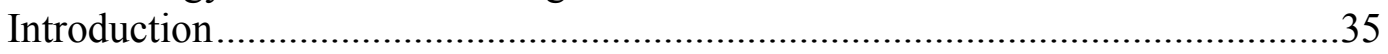

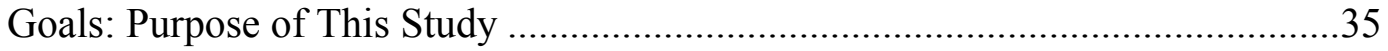

Research Questions: What Do I Want to Learn, Understand, and Accomplish? ..35 


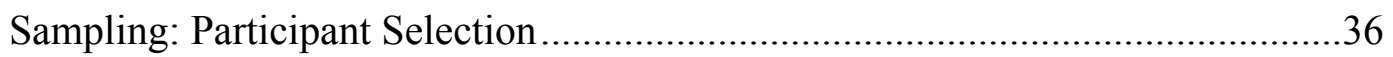

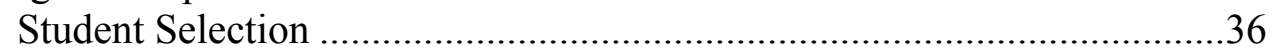

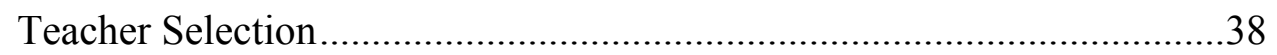

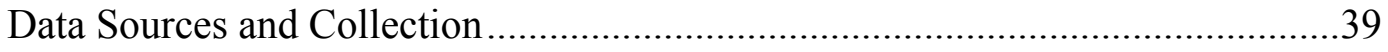

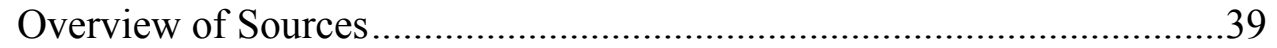

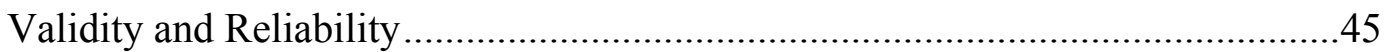

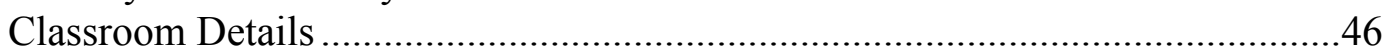

Description of Class Period ............................................................44

Description of Student Participants ........................................................47

Description of Unit: What Happened in Class Before the Unit of Study? ............51

Data Analysis Overview ............................................................................58

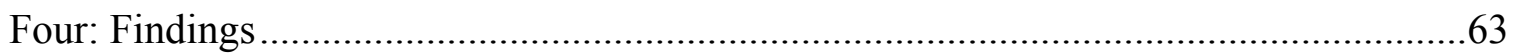

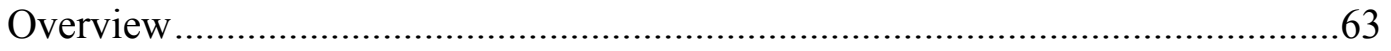

Coding Model for Data Source \#1: Reflection Surveys ..................................64

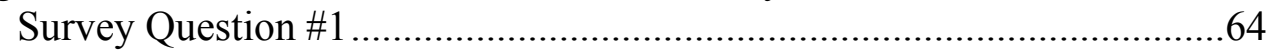

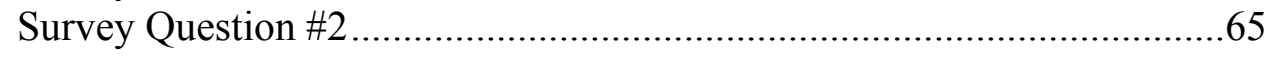

Survey Question \#3 .....................................................................65

Survey Question \#4 .......................................................................66

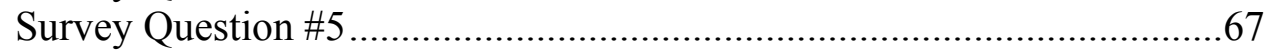

Survey Question \#6....................................................................68

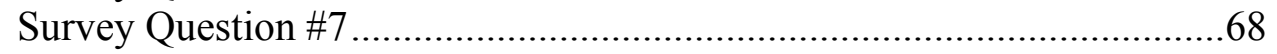

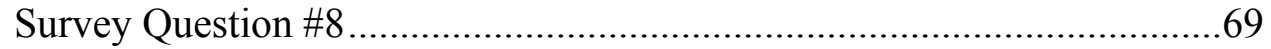

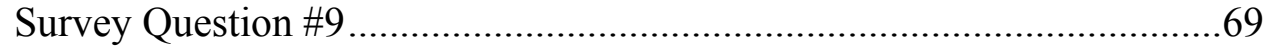

Survey Question \#10 ........................................................................69

Coding Model for Data Source \#2: Transcriptions of Socratic Questioning

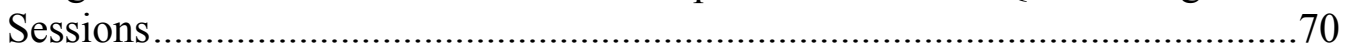

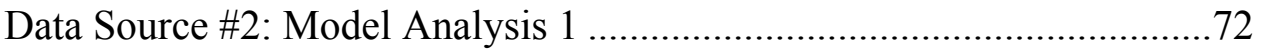

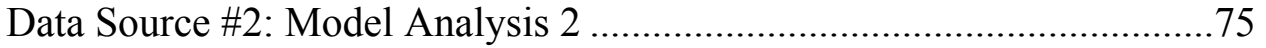

Data Source \#2: Model Analysis 3 .....................................................79

Coding Model for Data Source \#3: Transcriptions From One-On-One

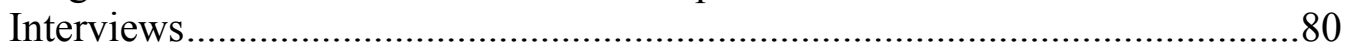

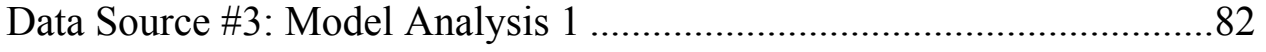

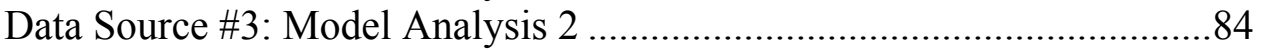

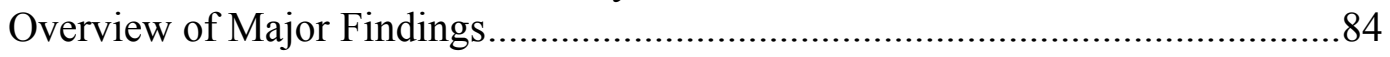

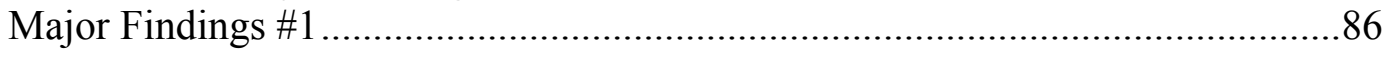

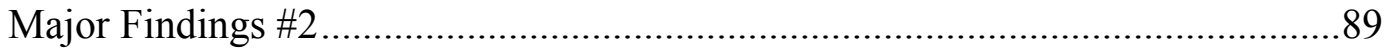

Five: Conclusions, Implications, and Further Research ..........................................94

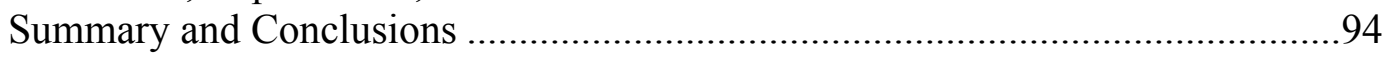

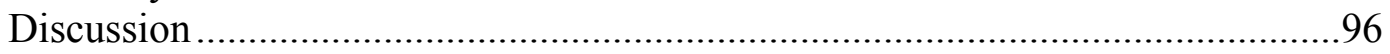

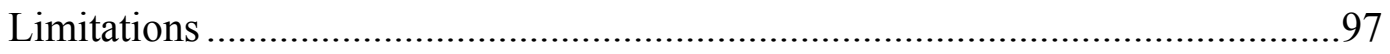

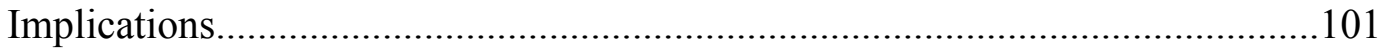

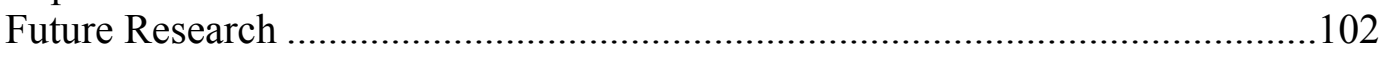




\section{Appendices}

A Informed Parent Permission Letter..............................................................110

B Informed Assent to Participate in Research ......................................................113

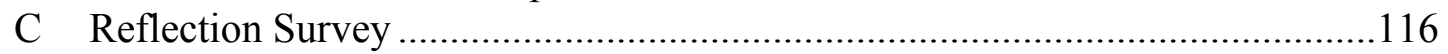

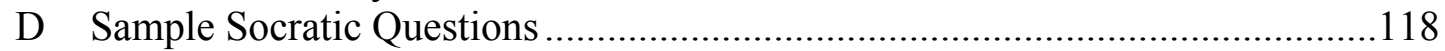

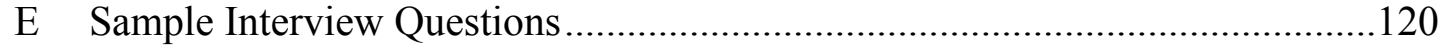


List of Tables

Table

1 Student Participant Information: Gender, GPA, Race/Ethnicity ........................50

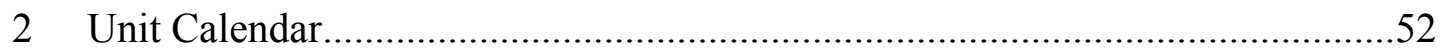

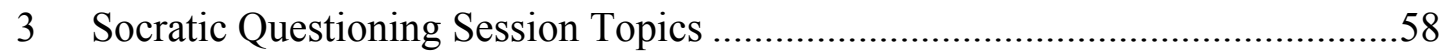

4 Question 1 Sample Category Comparison .................................................64

5 Question 2 Sample Category Comparison ..................................................65

6 Question 3 Sample Category Comparison ...................................................66

7 Question 4 Sample Category Comparison ................................................67

8 Question 5 Sample Category Comparison ................................................68

9 Question 7 Sample Category Comparison ..................................................68

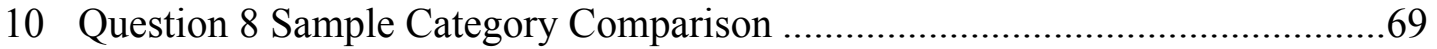

11 Question 10 Sample Category Comparison ................................................ 70

12 Sample Socratic Questioning Questions .................................................. 72 


\section{List of Figures}

$\begin{array}{lll}\text { Figure } & \text { Page }\end{array}$

1 Model Analysis Text Chunk \#17 .......................................................................76

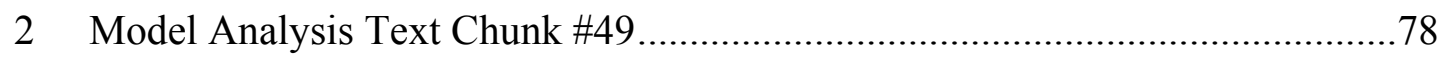

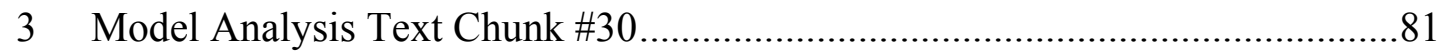

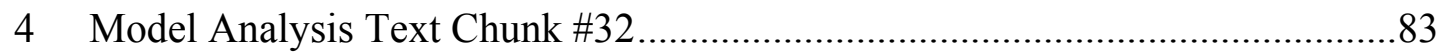

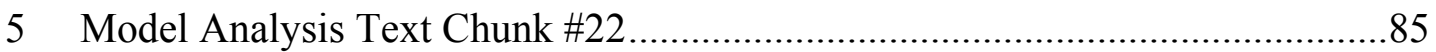




\section{CHAPTER ONE \\ INTRODUCTION AND PROBLEM}

Introduction

Socratic questioning has the potential to help students improve their skills in writing. It builds critical thinking skills and fosters learning by constructing new knowledge, and with the appropriate line of questioning, teachers can lead students to discuss, conceptualize, observe, analyze, apply, reason, evaluate, synthesize, and communicate with their peers (Elder \& Paul, 1998; Warren, 1994; Wiggins \& McTighe, 2005). Socratic questioning is often used with students in discussion. The questions are pointed towards literal, inferential, and evaluative perspectives, and these questions lead students to develop new assumptions. If used in conjunction with writing instruction, this line of inquiry can be used in the language arts classroom as a tool to support students in writing achievement.

If Socratic questioning is used to address writing standards, then students will have the opportunity to discuss, identify, change, and improve their views and skills in writing. For example, if Socratic questioning is used to address the skill of organizing one's ideas, then students will have the opportunity to discuss different ways of organizing their own writing. They will be able to identify strengths and weaknesses of different ways of organizing, and they will be able to discuss which organization style is most effective. The same can be said if Socratic questioning is used to tackle issues of 
conventions. Students will be discussing how, when, and why conventions are used, and, in turn, they will be learning how and when to use those conventions in their own writing.

Socratic questioning has become more suitable than ever for the language arts classroom and can help students improve their writing skills (Elder \& Paul, 1998; Warren, 1994; Wiggins \& McTighe, 2005). Ultimately, through Socratic questioning, students will have a deeper understanding of what it means to be an effective writer. It can lead students to improving their writing skills, and it should be used in the classroom as a method by which we get students to become better writers.

\section{Background}

Socratic questioning allows for discussion, differentiation, and infusion of critical thinking in rigorous learning environments. Questions can stimulate deeper thinking, provoke interest and inquiry, spark engaged discussion, and allow for greater intellectual focus (Elder \& Paul, 1998; Warren, 1994; Wiggins \& McTighe, 2005). If used to discuss and think about writing, Socratic questioning has the potential to allow for and support active and student-centered learning around writing. Students will be challenged to evaluate existing notions and techniques of writing, and they will be asked to generate new ideas while fostering creativity, discussion, and self-discipline (Warren, 1994). Thus, Socratic questioning can be used as a tool to help students identify and produce better writing.

\section{Significance}

As we wade through the 21 st century, the systematical concerns brought on by the No Child Left Behind Act and the increased academic requirements mandated by the 
Common Core State Standards can be felt by all stakeholders in the field of education (United States Department of Education, 2012). Students and teachers are being asked to demonstrate, produce, and achieve higher expectations than they ever have before, and they are starting to feel the impact of these new educational pressures brought on by new policy set at the federal and state levels (Marshall \& Gerstl-Pepin, 2005; United States Department of Education, 2012).

As a result of the dramatic changes that exist in today's world of education, common core writing standards and exams are beginning to stir new challenges for teachers and students alike. Between the new rigor of the Common Core State Standards and expectations, and the weight of the state exams, teachers are overwhelmed; they are searching high and low for any method or strategy that will help their students become better writers. The purpose of this study was to investigate if Socratic questioning is an effective tool for improving student perceptions of the writing process. The major aim of this study was to understand what methods or strategies improve students' perceptions of writing and the writing process. Thus, this study explores the notion that Socratic questioning can provide leverage for students when it comes to these new high stakes standards, and ultimately makes them better writers.

\section{Research Problem}

The ability to write effectively is a necessary skill that every student needs to have in order to succeed in the 21 st century of global education and instant communication (Achieve, 2011; Graham \& Perin, 2007; National Academies, 2006; National Assessment Governing Board [NAGB], 2013; National Council of Teachers of English [NCTE], 
2012; National Governors Association, 2005; National Research Council, 2008). The United States economy has seen drastic changes in the work force as manufacturing jobs have diminished and jobs that are based in information and communication have increased (James \& Unwin, 2013; NAGB, 2013; NCTE, 2012; White, Gunasekaran, \& Ariguzo, 2012).

In order to enter the work force with the skills they need, students need to be able to process and communicate information quickly and effectively. Dr. David Driscoll serves as the chair of the NAGB, an independent, bipartisan organization that oversees the National Assessment of Education Progress, also known as The Nation's Report Card. Driscoll argued that, "Writing is fundamental to effective communication. Students need to write clearly, logically, and accurately. We need to focus on supporting students beyond Basic levels so that they have a solid grasp of effective writing skills" (NAGB, 2013, p. 13).

According to national reports, students in the United States are not meeting expectations for writing tests and not meeting basic state writing standards (National Academies, 2006; National Research Council, 2008). In 2006, only $24 \%$ to $31 \%$ of students in grades 4,8 , and 12 met writing proficiency goals (Persky, Daane, \& Jin, 2003). According to the Nation's Report Card and National Assessment of Education Progress scores in writing from 2012, only $6 \%$ of eighth and twelfth graders performed at an advanced level in writing, $34 \%$ of students at the eighth and twelfth grade were proficient in writing, and $60 \%$ of all eighth and twelfth graders performed below proficiency in writing (NAGB, 2013). 
Thus, many students are not demonstrating proficient writing skills, and many of the nation's leading educational assessment and progress agencies believe that the $21^{\text {st }}$ century student needs to be proficient in writing and communication if they are going to be proficient and compete in the work force beyond the classroom (NAGB, 2013; NCTE, 2012). Therefore, as educators, we need to provide, maintain, support, and implement methods and techniques that will get students to be better writers, so that they can enter the work force with the appropriate skills.

\section{Problem Statement}

According to both state and national measures, student writing performance is weak; students' ability to organize ideas, create arguments, and demonstrate a command of conventions of Standard English grammar and usage is weak and ultimately not proficient. Socratic questioning, however, has the potential to help students think through their writing assignments and their own writing. Students will be heightening their critical thinking skills, promoting holistic views, and constructing meaning through dialogue (Graham \& Perin, 2007; National Academies, 2006; NCTE, 2012; Paul, 1993; Warren, 1994).

If Socratic questioning is used to address writing techniques, it can help students learn how to create arguments. They will have the opportunity to discuss the benefits and weaknesses of different ways of organizing their ideas. Through Socratic questioning, students can teach and learn how to effectively use different conventions and improve their grammar skills. Thus, Socratic questioning should be leveraged as a tool for 
teachers to help students meet the rigorous academic expectations, meet national standards, and become better writers.

\section{Research Questions and Methodology}

The purpose of this study was to understand what methods or strategies lead students to improve their perception of writing and the writing process. The research

question was: How can Socratic questioning improve students' perceptions of writing and the writing process? Since the ultimate goal in this study was to explore if and how Socratic questioning impacts student perception about writing, I used qualitative research methods as the framework for my research design.

An important reason why I chose qualitative methods for my design is because the design of something must fit not only with its use, but also with its environment. Qualitative researchers are interested in how participants interpret their own experiences, what meanings they attribute to those experiences, and ultimately how participants make sense of their lives in terms of the phenomenon of interest (Krathwohl, 2009). A strong qualitative research design requires an authentic constant assessment of the design components, as the goals, questions, and findings can be fickle, flexible, and surprising (Maxwell, 2005).

\section{Description of Socratic Method}

In the Socratic Method of education, teachers ask open-ended questions that are engaging and ultimately lead to discussion and a deeper analysis and inquiry of a topic or idea. These questions lead students to examine their own values, principles, understandings, assumptions, and beliefs (Elder \& Paul, 1998; Warren, 1994). The 
questions that are asked of the students enhance thinking and cognitive skills, and they challenge students to ask their own questions, which promote even further comprehension and thinking skills. Both the open-ended questions and the responses from the students allow them to be actively involved in their education while taking ownership of the things they have learned. Some researchers find that this mode of questioning is the most powerful teaching approach that allows students to construct their own knowledge (Elder \& Paul, 1998; Warren, 1994). Socratic questioning is used to examine previous understandings, helps construct new assumptions, and fosters discussion and critical thinking skills (Maiorana, 1991; Paul, 1993).

This method of teaching is based on the way Socrates communicated with his followers. Socrates searched for reasonable and logical ways to approach life; he simultaneously evaluated the systems, frameworks, and methods that establish teaching and learning. Socrates valued the learner as an active and necessary participant in the discovery of knowledge as truth, as he fathered the notion that learning is a process that is guided by questioning and self-reflection. In The Republic, Plato (1955) examined the dialogue that took place between Socrates and his students. Here, Socrates posed a series of strategic questions that helped his students discuss and create reasonable, logical, reflective, and new perspectives on worldly issues. This type of questioning and dialogue became Socrates' fundamental requirement necessary for learning and acquiring truths. This became known as the Socratic Method (Elder \& Paul, 1998). 
Socratic questioning has been adapted for the classroom teaching. For example, teachers using the Socratic Method ask students the following series of questions and lead them through a metacognitive discussion:

- What do you assume about the topic?

- What do you believe others assume about the topic?

- How and where did you find those assumptions?

- How are our collective assumptions similar or different?

- Do our assumptions make sense, logically relate, and connect to our world today? How, why, or can our assumptions be outdated or misguided?

- Can we construct a new assumption?

- Do you think others would agree with your new assumption?

For students, these types of questions are grappled with throughout the entire process of learning (Paul, 1993; Warren, 1994). Eventually, students learn how to ask these questions of themselves and their peers, so that a facilitator takes on less of a role in the learning process (Elder \& Paul, 1998). The Socratic Method has a spiraling approach; it does not end but continually changes perspectives as the learner changes. This method assumes that the criticizing, discussing, and reflecting on issues is never over; a learner will never stop constructing new knowledge.

\section{Summary}

As we enter into the information era, it is more important than ever to support students in becoming better writers. Federal and state educational agencies have increased expectations for students and teachers, and they have mandated new laws that highlight the need for more effective ways to support students in their writing skills (NAGB, 2013; Oregon Department of Education, 2012). Ultimately, student achievement 
and performance in writing is a vital part of a student's success in and out of school, and we need to find ways to help students become better writers.

National and statewide report cards and scores show that many students are not performing at the basic level of writing needed to graduate high school and enter the work force. According to the national standard, more than $60 \%$ of graduating students in 2012 were not proficient in writing (NAGB, 2013). There is a need for more effective methods for teaching and supporting students in their achievement in writing.

This study investigated using Socratic questioning as a tool to help students improve their perceptions of writing and the writing process. As it builds critical thinking skills and fosters learning by constructing new knowledge, Socratic questioning has the potential to improve student skills in writing. Socratic questioning ultimately requires an appropriate line of questioning that can lead students to discussion, analysis, and evaluation (Elder \& Paul, 1998). If Socratic questioning is used to address writing techniques and writing skills, then students will be discussing, analyzing, and evaluating different writing techniques and improving their own writing skills.

Assuming that teachers do not provide direct answers, Socratic questioning stimulates students' mind and requires them to engage in dialogue and self-reflection. Through the use of Socratic questioning, students are inevitably forced to be responsible for examining their own ethics, assumptions, and values as well as be able to share those ideas with their peers. The Socratic Method is a critical and demanding line of inquiry. It puts the world up to the light for examination, asks students what they think, and emphasizes the importance of accountability and insights. Ultimately, the use of Socratic 
questioning in the classroom can be beneficial to all students, and if it is used to discuss, analyze, and generate ideas about writing, then it has the potential to help students become better writers. 


\section{CHAPTER TWO \\ REVIEW OF THE LITERATURE}

In this chapter I describe the conceptual framework that informed my research. I describe Constructivism, Social Constructivism, and discuss how Socratic questioning fits in a Social Constructivist classroom. Next, I include my Literature Review that addresses the importance of questioning in the classroom, different types of classroom questions, and the influence of Socrates on questioning. Then I list and examine research that used the Socratic Method. I highlight the importance of critical thinking, identify the issues with power relationships in the classroom, and provide a brief description of the evolution of writing instruction.

\section{Conceptual Framework}

A conceptual framework is the "system of concepts, assumptions, expectations, beliefs, and theories that support and inform your research" (Maxwell, 2005, p. 33). There are the essential questions to ask when approaching one's conceptual framework, theoretical foundations, and personal beliefs on teaching and learning: What is learning? Who discovers or constructs it? Where is the knowledge held? I believe that learning is a very complex process that weaves together past experiences, environmental influences, community tools, emotional reactions, and cognitive reflections to acquire, enhance, or change a learner's knowledge, skill, and worldview. This process forces researchers, philosophers, and theorists to focus on what happens when the learning takes place. The 
following section addresses theoretical underpinnings and personal beliefs that I will use to create my research goals, questions, and design.

\section{Constructivism}

Learners are builders (Ernest, 1994). This metaphor is widely accepted by many theorists who examine learning as construction and see learners as builders of their own knowledge. Constructivists argue that learners construct knowledge and meaning from interacting with their previous experiences and ideas; we use what we have, negotiate, assess, and build on it to create new ideas (Ernest, 1994; Mezirow, 2000; Phillips, 1995).

This metaphor, which describes learning as building, greatly differs from the metaphor that is used to describe learners as spectators in the behaviorist model. Both metaphors describe learners as subjects that do something. However, one is more passive than the other. The act of building implies that there is once something there to build with or on. In contrast to spectators, who passively acquire knowledge by watching others, builders are actively interacting with their previous assumptions. A spectator does not interact; he or she observes. These two metaphors help bring the distinction between behaviorism and constructivism into sharper focus. Thus, the relationship between knowledge and the learner is very different when applied to someone who watches learning happen and someone who constructs it for herself.

Phillips (1995) declared that, "human knowledge--whether it be the bodies of public knowledge known as the various disciplines, or the cognitive structure of the individual knower or learner--is constructed" (p. 5). Mezirow (2000) similarly argued that, "Learning is understood as the process of using a prior interpretation to construe a 
new or revised interpretation of the meaning of one's experiences as a guide to future action" (p. 5). He continued, "Learning occurs in one of four ways: by elaborating existing frames of reference, by learning new frames of reference, by transforming points of view, or by transforming habits of mind" (Mezirow, 2000, p. 19). Thus, constructivism demands that learners recognize how and when assumptions were constructed and what values and beliefs led them to these constructs.

In contradiction to Skinner's (1987) belief that internal processes do not play a role in the learning process, Piaget believed that knowledge is internalized by learners through assimilation and accommodation (Fosnot, 1996). In contrast to behaviorists, some of whom believe that knowledge can be transferred through modeling and observation, Piaget (1980) believed that there was more to learning than simply recalling coded information. "Fifty years of experience have taught us that knowledge does not result from a mere recoding of observations without a structuring activity on the part of the subject" (Piaget, 1980, p. 123). Piaget believed when learners assimilate, they integrate the new experience into an already existing structure without altering it. Piaget also believed that accommodation is the process of reformation that requires a learner to change one's mental representation of the world to fit new experiences (Fosnot, 1996; Phillips, 1995).

\section{Social Constructivism}

One important subtype of constructivism is social constructivism, which views learners as multidimensional unique individuals, with unique backgrounds, unique needs, and unique beliefs (Fosnot, 1996; Phillips, 1995). The complexity of the individual is 
encouraged, celebrated, and used as an integral part of the learning process. Social constructivists take into account the cultural background of the learner, as it colors the knowledge and truth that the learner creates in the process of learning (Ernest, 1994; Mezirow, 2000; Phillips, 1995). The main difference between constructivism and social constructivism is summarized by a metaphor that Ernest (1994) used to describe learners as persons in conversation. While in dialogue, learners share and collaborate to create knowledge; knowledge is, thus, held both in the individuals and within the social group. Many constructivists argue that our knowledge is a result of our past experiences and how we perceived those experiences (Ernest, 1994; Fosnot, 1996; Mezirow, 2000; Phillips, 1995). We can never say that two people have produced the same construct, and that is why it is necessary to disclose, negotiate, and share previous assumptions socially; learners do not come with the same set of knowledge and constructs. Phillips (1995) argued learners must take an active role in learning and also recognize the social nature of learning to accommodate and incorporate that diversity that inherently exists when more than one learner is involved in the learning process.

Social constructivists acknowledge the importance of discussion with peers, and they believe that sharing ideas and experiences is vital to the learning process (Fosnot, 1996; Mezirow, 2000; Phillips, 1995; Vygotsky, 1978). Mezirow (2000) went so far as to argue that discussion is one of the most important parts of learning. He bought up the notion that ideas need to be "tried on" by our peers so that they can be examined. This idea of trying on other people's assumptions helps learners question and criticize their own ideas. 
This metaphor, which describes learners as persons in dialogue, and this social aspect of constructivism are strongly influenced by Vygotsky's (1978) work. One notion that Vygotsky supported was the need for collaboration among learners. Vygotsky's Zone of Proximal Development is defined as the distance between the actual developmental level that a learner achieves with independent problem solving, and the level of potential development that a learner determines under guidance or in collaboration with more capable peers. Thus, Vygotsky presented the notion that discussion with someone more capable is necessary for a less capable learner to gain knowledge, and in doing so he supports the metaphor that defines learners as persons in conversation with one another.

There are several points of weakness that hinder and limit access to knowledge in the constructivist and social constructivist models. First, the constructivist method works best for learners with well-developed metacognitive skills and thus assumes that it is a conscious rational process. If students do not have experience in critical thinking, then construction of knowledge is hindered and can be extremely difficult to create. Second, for students to be successful in the constructivist model, there needs to be a safe and inclusive environment where students can feel safe to examine their beliefs with others; if students feel apprehension about sharing, examining, and constructing new assumptions in an unsafe environment, then access to and creation of knowledge can be difficult.

Like all other learning theories, power dynamics need to be examined when considering student access to knowledge. I believe that the power relations that exist in a social constructivist classroom are at first uneven, because the facilitator has more power. For example, in a social constructivist classroom, the facilitators have more power 
because they know how to guide the discussion and ask the right questions (Phillips, 1995). They have the capability to make or direct a change. However, the nature of social constructivism is that students will eventually learn how to guide the discussion and ask the right questions for themselves (Mezirow, 2000). This allows learners to take on more ownership of their own learning. The less input the facilitator has, the less capability he or she has to direct and create change. Therefore, as the role of the facilitator and learner changes, so do the power relationships. If the construction of knowledge is continual and has an evolving nature, then the power relations are also evolving.

\section{Social Constructivism and the Socratic Method}

Learners do not observe others, nor do they engage in the modeling process or change behaviors through conditioning and reinforcements. The metaphor, which describes learners as spectators, does not apply to the Socratic Method and critical thinking because cognitive and internal processes take place when a learner participates in this method (Paul, 1993; Wiggins \& McTighe, 2005). Thus, learners are not just spectators when they engage in the Socratic Method. Unlike behaviorism, the Socratic Method leads to the construction of knowledge rather than a discovery. Although Bandura's (1986) Social Learning Theory may seem to fit through the lens of social learning, in the Socratic Method, learning is not observed and then reproduced; learning is not just a copy of a copy. Learners are not spectators.

The design of the Socratic Method and the practice of one's social, critical thinking, and discussion skills can be directly used in a social constructivist classroom. The Socratic Method is most suited for a social constructivist approach because learners 
are builders in discussion (Elder \& Paul, 1998; Ernest, 1994). This metaphor directly applies to the Socratic Method because learners are constructing knowledge from their previous assumptions by discussing, reflecting, questioning, criticizing, and interacting in social discussion with their peers. Thus, in the Socratic Method, like in social constructivism, learners are builders and constructers of their own knowledge, but they are also builders in discussion. As Ernest (1994) argued in his persons-in-dialogue metaphor, there is a social component to constructing one's knowledge that plays out through discussing and assessing issues with others. Thus, social interaction, discussion, and assessing other assumptions are critical components of the Socratic Method. Much like the Socratic Method, Fosnot (1996) argued that a social constructivist classroom "is seen as a mini society, a community of learners engaged in activity, discourse, and reflection" (p. ix).

Similar to the Socratic Method, a social constructivist teacher sets up problems and monitors student discussion, exploration, guides the direction of student inquiry, and promotes new patterns of thinking (Mezirow, 2000). Students are given the autonomy to direct their own explorations, exchange their personal views, and test them against the ideas of others (Mezirow, 2000; Phillips, 1995). In addition, the Socratic Method calls for the traditional hierarchy of a teacher, as one who knows all and tells all, to be dislodged (Elder \& Paul, 1998; Warren, 1994). This is again closely related to social constructivism. The Socratic Method asks teachers to be facilitators. It also asks learners to take on more responsibility and ownership of their knowledge. Moreover, in social 
constructivism, like the Socratic Method, autonomy, empowerment, and social interaction are vital to the learning process (Fosnot, 1996).

Like the Socratic Method, the social constructivist model argues that the responsibility of learning belongs to the learner (Fosnot, 1996). Fosnot (1996) emphasized that learners construct their own understanding and that they do not simply mirror and reflect what is read. Like Fosnot, Elder and Paul (1998), Paul (1993), and Warren (1994), Phillips (1995) indirectly argued against behaviorism in the classroom. Phillips stated that behaviorism promotes learners to be spectators and argued that, "the construction of knowledge is an active process, but the activity can be described in terms of the individual cognition or else in terms of social and political processes" (p. 9).

\section{Introduction for Literature Review}

This literature review includes and synthesizes various important areas of educational inquiry. The citations, articles, books, and research reports reviewed for this purpose provide an integrated perspective on questioning techniques used in the classroom. Specifically, my literature review investigates how classroom questioning affects student learning and critical thinking skills. In the first section, I discuss the purpose and role of questioning strategies. Next, I define and describe the types of questioning. Then I discuss the significance of Socrates in the world of questioning strategies. Specifically in this section, I present a review of the Socratic Method, including three fundamental characteristics. Then I summarize many different research studies that use the Socratic Method in a classroom to examine its effect on student perspective and learning. Next, I discuss how research in questioning strategies leads to 
assumptions about evidence of the significance of critical thinking skills. Specifically in this section, I present the problem of choosing just one definition for critical thinking and the various ways it has been defined. Finally, I include a brief history of writing instruction. In this brief history, I describe the progression and advancement of writing instruction and why the theory behind writing education has changed over the years.

\section{Importance of Questioning in the Classroom}

Because of the relationship to critical thinking, questioning strategies have been examined by many educational researchers for over a century (Harrop \& Swinson, 2003; Marzano, Pickering, \& Pollock, 2001; Myhill \& Dunkin, 2002; Sahin \& Kulm, 2007; Stevens, 1912; Winne, 1979). These researchers continue to explore the relationship between questions and critical thinking and argue that questions have a significant influence on social and academic responsibility. Case studies on questioning behaviors and patterns of teacher questions have rediscovered what early revolutionary thinkers already knew. Approximately $80 \%$ of a teacher's teaching in school was spent asking questions (Myhill \& Dunkin, 2002; Stevens, 1912).

These findings reveal that questions saturate and dominate classrooms, and it was no surprise to find that it is equally as dominating in the world of educational research. Harrop and Swinson (2003) closely researched the following questions used in classrooms: What can questions accomplish? What are the best questions? Marzano et al. (2001) looked at the effect questions have on critical thinking skills. These are the most common and significant questions that overlap when synthesizing research on classroom questioning strategies. 
Although these researchers agree on the importance of questioning strategies, they also believe that questions serve many different purposes. Some argue that the purpose of questions is to provoke students to analyze their thoughts critically (Ramsey, Gabbard, Clawson, Lee, \& Henson, 1990). Others believe that questions fulfill their full potential only if they can initiate discussion (Cotton, 1989). Some researchers believe that questions should challenge students to discover new ideas and new perspectives. The right question will motivate students to take risks in their own education (Schurr, 2000). While many of the researchers acknowledge that the predominant purpose of questions has been and still is to check and evaluate students' understanding, they also believe that questions can do much more than that (Cotton, 1989; Marzano et al., 2001, Sahin \& Kulm, 2007). They argue that questions can enhance thinking skills so that students can enhance or even change existing assumptions they have about topics discussed. Although some believe that purposes do vary, questions are ultimately an important and powerful tool used in the classroom.

\section{Types of Classroom Questioning}

Since my study is rooted in a specific type of questioning strategy, it is important to take a more careful look at the quality of questions that exist in the classroom today. Along with the research on the importance of questioning strategies, there is an equal amount of research on the types of classroom questions used by teachers. In the research read for this review, one thing researchers can agree on is that questions can be categorized based on the cognitive level of student understanding. According to Cotton (1989), questions are dualistic; they are divergent or convergent. They could have many 
answers or simply one. While Black (2001) agreed that questions are dualistic, but he went on to argue that it is much broader than simply saying a question is divergent or convergent. Black noted there are two broad types of teacher questions: low-level and high-level. Low-level questions are closed, direct, and require students to recall knowledge. High-level questions are open-ended, interpretive, evaluative, and require students to elaborate, defend, and synthesize. Sahin and Kulm (2007) argued that lowlevel questions are used in the classroom $80 \%$ of the time by the teacher, while high-level questions are used $20 \%$ of the time by the teacher.

Other researchers believe that questions are not dualistic but rather can be categorized according to a hierarchy of knowledge (Ilaria, 2002). For example, Bloom (1956) found that questions are ordered or categorized based on the content or complexity of their meanings. Bloom's taxonomy categorizes questions in the following six levels: knowledge, comprehension, application, analysis, synthesis, and evaluation. Martino and Maher (1999) argued that higher level questioning such as analysis, synthesis, and evaluation are forms of probing questions. Probing questions can be used for justification and explanation. These types of questions allow teachers to delve into and better understand student expression and interpretation to assess critical thinking skills (Marzano et al., 2001; Moyer \& Milewicz, 2002).

Aside from the many types of questions, some researchers would argue that the quality of the question is more vital to student achievement and learning. Walsh and Sattes (2011) have the belief that a quality question is purposeful, engaging, and consequential. They noted that quality questions are aligned with the objectives of the 
lesson, promote children's interest and class involvement, and result in learning. Walsh and Sattes provided four characteristics of quality questions: (a) promote one or more carefully defined instructional purposes, (b) focus on important content, (c) facilitate thinking at a stipulated cognitive level, and (d) communicate clearly what is being asked (p. 23).

\section{Influence of Socrates and the Socratic Method on Questioning}

The Socratic Method stems from the Greek philosopher, Socrates. Socrates is known for his philosophy on the examined life and his passion for discussion. He fathered two key components of critical thinking and intellectual integrity that have become widely respected contributions to the field of education. According to different researchers, his first contribution exposed the need to think well, and the second was the Socratic Method (Paul \& Elder, 2007). The Socratic Method is commonly known as a student-centered discussion that stems from a probing question and leads to numerous possible answers.

Socratic questioning is a product of this method. It is when a teacher provides a series of questions that will ultimately encourage the student to find a new perspective on life (Paul \& Elder, 2007). The purpose of these questions is to stimulate social, personal, and academic responsibility. Socratic questioning is a type of questioning that many leaders, educators, and teachers today have begun using in their classrooms (Black 2001; Fasko, 2003; Warren, 1994).

There have been many studies that define and categorize the Socratic Method. Warren (1994) wrote an essay that argued there are three significant and distinguishing 
characteristics to the Socratic Method. Warren argued that the first distinction of the method is that thinking should be a social activity. Social thinking sets the stage for dialogue. Through discussions, participants agree to collaborate and cooperate. Social thinking allows participants to address a problem or issue, while they struggle through challenges that inevitably arise while debate and discussion take place. Warren next declared that knowledge cannot be claimed. To engage properly in the Socratic Method, participants must acknowledge that their conceptions and beliefs may be insufficient or misleading in context. Essentially, participants should question and criticize their knowledge and be critically reflective of their previous assumptions. The third fundamental feature of the Socratic Method is that knowledge cannot be inertly or inactively absorbed or taught. Warren argued that thinkers must do the intellectual heavy lifting. Obtaining knowledge is an active process that requires thinkers to engage. In other words, Warren stated that in order to be a skilled reasoner, thinkers must consciously participate in creation and collaboration.

\section{Socratic Method and Research}

In addition to Warren, others researchers also believe that the Socratic Method has significant implications for education (Fasko, 2003; Paul, Elder, \& Bartell, 1997). The power of the Socratic Method rests in the critical thinking skills that allow learners to construct new knowledge and assumptions that will positively contribute to reconstructing our society for democratic purposes. As participants explore, question, criticize, and discuss, they will develop a sense of social and academic responsibility (Fasko, 2003; Paul et al., 1997). 
In a qualitative research study in a third grade classroom to promote higher level thinking skills, Shain (1995) examined the use of the Socratic Method. Shain concluded that the Socratic Method was an effective method, and the open-ended nature of the method provided the opportunity for students to examine, interpret, listen, debate, and analyze literature. In another qualitative examination of the Socratic Method, Mee (2000) explored the perception of several seventh graders. Mee's main goal was to see if the Socratic Method had any positive impact on a student's motivation for learning. By giving them a sense of confidence, capturing their attention, and providing relevancy, the use of the Socratic Method enhanced the motivation these students had to learn.

Garlikov (2000) used quantitative methods to examine the Socratic Method in a math class to excite curiosity, promote academic success, and arouse reflection. Garlikov proved that through this process, students were able to discover ideas of their own, discuss opposing ideas with their peers, and achieve higher scores on a state math test as seen through a pre and post examination. In 2010, Croasmun used a quantitative study to explore the relationship of self-efficacy to the lecture method and Socratic Method in adult learners. He concluded that Socratic questioning and dialogue was an effective instructional strategy that helped meet the educational and social needs such as selfdirectedness, self-efficacy, and autonomy of the adult learner.

In another quantitative study, Ward (1994) used the Socratic Method in his science classroom to prove that the open-ended questioning process can enhance analysis, evaluation, and hypothesis during the scientific method. Carnevale (2005) also explored the Socratic Method by means of a quantitative study. Carnevale examined an online law 
school, whose students used the Socratic Method in their classes to discuss, evaluate, debate, and examine judicial rulings and philosophical notions of law. Both Ward and Carnevale presented results that proved the Socratic Method to be an effective tool that helps students achieve academic success.

Boghossian (2006) examined the effects of the Socratic Method using mixed methods with inmates in Portland, Oregon. His research proved that the inmates developed an appreciation for the curriculum and felt empowered while using critical thinking skills and metacognitive reflective processes. Moore and Rudd (2002) also published a mixed methods study that used the Socratic Method in several different agricultural classes. With mainly interviews, pretests and posttests, they proved that as students became more actively involved in the learning and questioning process, they were able to provide better evidence, debate alternating ideas, and ask their own probing questions.

\section{Importance and the Problem of Defining Critical Thinking}

Scholars like Cotton (1989), Bloom (1956), Paul (1993), Elder and Paul (1998), and Warren (1994) stated that critical thinking is the most important goal and argued for its implementation in education. They acknowledged the claim that human thinking is fallible and misguided, but they also argued that it has the potential to change and improve our society.

Despite the almost collective outcry for teachers to engage their students in critical thinking, there is little to no consensus on its definition, application, or effect in the field of education (Ramsey et al., 1990; Schurr, 2000). One definition can be shortsighted and 
too biased towards a single field. Emphasizing only one definition of critical thinking can be detrimental and works against its flexibility to work within all domains of education. The following are several definitions that scholars have claimed fully encompass the application and effect of critical thinking skills in the field of education:

Glaser (1941) defined critical thinking as follows:

The ability to think critically ... involves three things: (1) an attitude of being disposed to consider in a thoughtful way the problems and subjects that come within the range of one's experiences, (2) knowledge of the methods of logical inquiry and reasoning, and (3) some skill in applying those methods. (p. 5)

Glaser's understanding of critical thinking states that thinkers need to be willing to investigate problems and issues relevant to life. Glaser also emphasized that critical thinkers need to use well founded evidence that is not subjective or socially conformed.

Ennis (1996) wrote, "Critical thinking is a process, the goal of which is to make reasonable decisions about what to believe and what to do" (p. 17). Ennis argued that critical thinking is not a goal in and of itself but a complex process. The goal of this process is to live life with reason. Ennis' perspective on this term is closely related to Socrates' belief that a life is only worth living if it is examined.

Paul et al. (1997) wrote that critical thinking is "the intellectually disciplined process of actively and skillfully conceptualizing, applying, synthesizing, and evaluating information gathered from or generated by observation, reflection, reasoning, or communication, as a guide to belief and action" (p. 4). Much like Glaser (1941) and Ennis (1996), they stated that critical thinking is a process, but more specifically they argued that it is conceptual and requires a certain level of rigor. Thus, since everything 
relies on ideas, the degree to which one can direct and control that idea is directly related to the level of one's thinking.

Given the complexity of what it means to be a critical thinker and its implications for the field of education, no single definition will ever be enough. One single understanding will emphasize basic ideas that other definitions do not. One definition will magnify strengths that another definition does not even acknowledge. Glaser (1941) described critical thinking as a three-step process and emphasizes that evaluation of evidence is necessary. While Ennis (1996) also agreed that it is a complex process, he places more significance on reasoning and decision-making. Paul et al. (1997) argued that critical thinking is a process too, but they also believe it is conceptual. Thus, the lack of one single definition that scholars can agree on might be the reason why implementation in the classroom can become very difficult. That is why it is important to identify my own definition of critical thinking in terms of this study. I believe critical thinking requires reflection and supports problem solving. Therefore, in order to be critical thinkers, students must use metacognitive skills so that they can work together and problem solve.

\section{Power and Poverty in the Classroom}

When using discussion as a tool for instruction in the classroom, it is important to recognize the different relationships that exist with students. When asked questions that require students to speak and share, students might feel scared and vulnerable in front of their peers. Different power relationships might hinder students from being able to fully engage in discussion and questioning. Power and poverty are controversial yet necessary 
topics to address when considering academic success (Gallas, 1998; Himley, 1997; Manke, 1997). Research shows that one of the most prominent power dynamics in the classroom is gender dynamics. The notion that boys are more outgoing than girls is true for gender behavior and interaction in the classroom. For example, Manke (1997) argued that the simple fact of being a boy allows them to be more assertive and confident when learning new things. He stated that being assertive and confident are learned behaviors that most commonly align with the male gender, and that boys are generally going to be more dominant in groups and discussions. This has a crucial impact in the classroom, because girls may be overpowered and less vocal. It shows that teachers should be aware of the gender dynamics that exist in their classrooms, and they should address these issues when creating curriculum and classroom environment. Gallas (1998), however, has the belief in a social constructivist perspective when considering power relationships in the classroom. She argued that power is mutually constructed and negotiated between the teacher and the student. Ultimately, Gallas asserted that teachers have the ability to sculpt and change power dynamics by creating a structured and equal space in their classrooms. Nonetheless, differing power dynamics within the classroom, including gender interactions, exist. Teachers should manage and build positive equal learning environments for all students.

Power dynamics are not the only hidden factors that might impact students in a classroom. Poverty plays a major role in how successful students can be academically. Many studies have documented the association between family poverty, achievement, and classroom behavior (Brooks-Gunn \& Duncan, 1997). Brooks-Gunn and Duncan 
(1997), Knapp (1995), and Rumberger and Palardy (2005) all agreed that socioeconomic status plays not only an important role, but almost a defining role, in the academic ability of most young children. Knapp stated that environment, social upbringing, and the teacher can be more influential as children grow older, but that poverty is a negative factor in academic success. Brooks-Gunn and Duncan went even further to argue that poverty is not only a negative factor when learning how to read and write, but they also stated that poverty is a negative factor when it comes to proficient speaking skills. Brooks-Gunn and Duncan stated that residential community and residential address are connected to learned dialect, and thus, speech can be dramatically impacted if a child lives in a high poverty area. This is crucial to note as Common Core Curriculum Standards are being enforced and include Speaking and Listening skills. Thus, students who live in these high poverty areas are going to need extra resources, guidance, and support from their teachers and peers to perform at proficient levels when considering achievement in assessed speaking skills.

\section{Evolution of Writing Instruction}

The progression and advancement of writing instruction is marked by drastic changes in technology, resources, and instructional theory. However, before theory of instruction was argued, implemented, and reinvented, there was a challenge in defining what it meant to write. In today's 21 st century of global communication, writing is a complex, crafted, and multifaceted way of communicating a variety of emotions, information, and knowledge. I call this unsatisfactory because most language arts teacher 
knows that there is more to the style, craft, and the purpose of writing than one could summarize in one sentence.

When examining our earliest education systems, there was a very narrow definition of writing that was simplified to "spelling" (Popkewitz, 1987, p. 88). Some of the earliest accounts of writing instruction stemmed from colonial education. This writing instruction was limited and taught by having students copy various passages of written work, so that they could replicate correct spelling and adequate penmanship (Monaghan, 2005).

Even though early writing instruction seems perfunctory, resources for writing education, before and around the colonial era, were rare and difficult to come by (Popkewitz, 1987). Twenty-first century teachers take for granted what was one of the biggest challenges in the history of writing: finding paper and a pencil to write with. Although conceptualized in the early 1500 s, pencils were not mass produced until the early 1700s. During the colonial era, school children mainly used quills, which were expensive, difficult to use, and extremely messy. In addition, children were thought not to have the motor dexterity required to write with a quill until they were 7 years old (Monaghan, 2005).

Writing as composition began to develop and evolve in the late 18th century and became more than just spelling and penmanship (Monaghan, 2005). However, writing instruction was still rooted in the practice of copying various passages and forms of composition. School children were mainly asked to copy letter writing, and schoolbook manuscripts consisted mainly of model letters (Monaghan, 2005). 
Grammar instruction was not embedded into the English classroom until the middle of the $19^{\text {th }}$ century. Penmanship became far less important than correct grammar. Good writing now was characterized by "a mastery of capitalization, punctuation, and syntax as well as correct spelling and pleasing handwriting" (Popkewitz, 1987, p. 89).

In addition to grammar instruction, the oratory culture of literary debate and formal speaking transformed college communities in the late 1800s (Murphy, 1990). These debate societies argued the purpose of writing and rejected the notion that the content of composition should solely serve vocational or civic functions. Students began to argue that emotion, style, and creative intention should exist in writing composition (Murphy, 1990).

These revolutionary ideas of writing and writing instruction began to filter down into lower grade classrooms and helped further define writing as composition. At the higher grades, students were responding to literature in their writing and reflecting on what the literature meant (Murphy, 1990). Thus, by the end of the 1800s composition had evolved "as an attempt to adapt rhetoric to dramatically changed conditions both inside and outside the academy, conditions produced by the industrial revolution and the new middle class and professional mores" (Murphy, 1990, p. 178).

Consequently, the start of the 20th century marked a drastic change in the approach to writing instruction. Writing instruction no longer consisted of merely drills and classical studies, but had personal and social communication functions (Brand, 1980). Writing students were being asked to take interest in their environment, observe the human condition, and improve their ability to organize written expression. Creativity in 
writing and organization was a means of identifying the truly talented students, while conformity in their writing was a means of identifying the weak writing students (Brand, 1980). Students began to examine prior experience, mediums of expression, imaginative themes, and social behavior (Murphy, 1990).

Since the end of the 20th century, writing instruction has begun to take on many forms. Hull and Rose (1989) described the changes in writing instruction in more recent history:

In the last 20 years, writing research and instruction have been turned on their heads ... But we've heard just half of the tale. There has been another great revolution in our thinking about writing in recent years, and it has come from learning to view writing as a process that is embedded in a context. (pp. 105, 109)

Flowers and Hayes (1981) believed that writing was a process that can be best understood as a set of thinking processes rather than a set of stages. Murray (1972) argued that many language arts teachers are more concerned with the product of their students, rather than the process. Murray called this the "product paradigm" and asserted that

writing that should be taught as a process of discovery through language. It is the process of exploration of what we know and what we feel about what we know through language. It is the process of using language to learn about our world, to evaluate what we learn about our world, to communicate what we learn about our world. (p. 4)

Murray believed that teachers should teach "unfinished writing" to celebrate the notion that writing is "language in action" (p. 15).

Writing as a craft was highlighted by Graves (as cited in Walshe, 1981), "We must teach it as other crafts are taught: in studio or workshop conditions" (p. 8). Although Graves supported his notion of the craft of writing by emphasizing the importance of teachers writing with students, Carroll and Wilson (1993), in Acts of Teaching: How to 
Teach Writing, also suggested that product should not be a teacher's main concern when approaching writing instruction, and that the process of writing is more important. Carroll and Wilson conducted a study with twelfth graders and verified that "writing on command produced stilted, formulaic pieces of discourse and caused most students to regard writing as something you do only when someone in authority forces you" (p. 13).

Much like the other educational leaders and thinkers of his time, Shaughnessey (1977) referred to the socialization process that occurs when student writers see their writing in alignment with the writing of others (pp. 287, 288). However powerful these theories have been, there remains a distance between them and their implementation in the classroom. In spite of the theories that inspired English teachers like Shaughnessey to view writing as communication and to value the writing process, Raimes (1991) explained, "Teachers did not all strike out along this new path. The radical changes that were called for in instructional approach seemed to provoke a swift reaction, a return to the safety of the well-worn trail where texts and teachers have priority" (p. 410).

Despite all the earlier thinkers and educators who sought do more than just deposit information into the minds of their students, writing instruction today seems aligned with Freire's (1984) banking model. Rather than allowing students to use their writing as a means of expressing their thoughts and ideas, and valuing those thoughts and ideas, often teachers "deposit" into students the knowledge that the teacher deems relevant: what is a thesis statement, a five paragraph essay, and a proper conclusion.

The Socratic Method has a place in constructivism, social constructivism, and, more importantly, the classroom. Many versions of classroom Socratic practices have 
been studied and researched with valuable results. This study has a place in that field of research because it addresses the notion that Socratic questioning might have an impact on student writing. The next chapter uncovers the details of this research study and explores how it has a place in the field of research connected to Socratic practices. 


\section{CHAPTER THREE \\ METHODOLOGY AND RESEARCH DESIGN \\ Introduction}

Qualitative researchers are interested in how participants interpret their own experiences, what meanings they attribute to those experiences, and ultimately how participants make sense of their lives in terms of the phenomenon of interest (Krathwohl, 2009). A strong qualitative research design requires an authentic constant assessment of the design components, as the goals, questions, and findings can be fickle, flexible, and surprising (Maxwell, 2005). An important reason why I chose qualitative methods for my design is because the design of something must fit not only with its use, but also with its environment. In the following sections, I draw a line that connects my research goals, my research questions, my data sources, my possible approaches to analyzing my future data, and my recognition of the validity and limitation of this design.

\section{Goals: Purpose of This Study}

The purpose of this study was to investigate if Socratic questioning is an effective tool for improving the perceptions of the writing process.

\section{Research Questions: What Do I Want to Learn, Understand, and Accomplish?}

In this study, I investigated the following research question: How can Socratic questioning improve students' perceptions of writing and the writing process? 


\section{Sampling: Participant Selection}

\section{Student Selection}

I used purposeful and criterion-based selection as my sampling method. "Purposeful sampling is based on the assumption that the investigator wants to discover, understand, and gain insight and therefore must select a sample from which the most can be learned" (Merriam, 2009, p. 77). Deliberately choosing student participants provided more confidence that my conclusions adequately represented the population of students I was trying to examine. Deliberate selection also helped illuminate the phenomenon I was trying to uncover: In what ways does Socratic questioning impact student writing? Since nonprobability sampling raises concerns about the representativeness of the sample, it was important to recognize and compare demographic characteristics of the sample population; it was vital to choose information-rich participants.

Merriam (2009) suggested that to begin purposeful sampling, the researcher must determine the selection criterion essential in choosing participants who will be information-rich. Therefore, in order to select information-rich participants, the researcher must spell out specific attributes that are essential in choosing those student participants and explain why those attributes are important (Merriam, 2009).

Krathwohl (2009) argued that in purposeful sampling, small samples of extreme or deviant cases are used to view a phenomenon in an extreme light, with the hope of finding some clues about more normal cases. Although external generalizability will be compromised with such a small sample, deliberately choosing a small sample of 
participants can test the robustness of the study and strengthen the logic of the methods being used (Krathwohl, 2009).

To collect information-rich participants, to overcome class-size barriers, and to keep a small sample size, I purposefully selected 10 students to participate in this study. At an average of 40 students in a classroom, putting students in smaller groups for questioning and discussion was a more effective way to gain knowledge and value out of student discussions. In order to purposefully select those 10 students, I first eliminated possible student participants who had language or learning disabilities. Even though exclusion of some students creates a bias and a limitation in the study, I did not want to include students with any kind of learning or language barrier, so this excluded any student who was identified as Special Education, early English Language Learner (ELL), had a language-related Individualized Education Program (IEP), or had a speaking 504 plan. Students on a modified diploma are given individualized work and do not complete the same assignments as a student who is on a regular graduation diploma. These students receive a different and modified diploma. Students in our early ELL program are categorized as being in the country fewer than 14 months. Some of these students speak and understand very little English. Excluding students with these learning and language disabilities allowed me to uncover truths about my topic that might otherwise be hindered or blocked by a student's inability to speak, discuss, contribute, or be able to understand the questions that were asked during Socratic questioning.

Once I narrowed down the pool of students for language barriers and Special Education identification, I randomly chose the class period I would use, and then I sent 
home consent and forms for that class period. Consent forms were sent home in English, Spanish, and Russian. It is important to note that very few Spanish and Russian forms were returned. After I collected returned forms, I randomly chose 10 students from that list of students who had consented to be part of my study. Even though gender, socioeconomic status, and grade point average (GPA) should be considered in the study, I chose participants at random. After I randomly chose 10 students to be part of my study, I randomly grouped the rest of the students into Socratic seminar groups. All students in the class would participate in Socratic questioning, so all students needed to be placed in groups.

\section{Teacher Selection}

After careful deliberation about which teacher to use in this study, I chose myself to be teacher as researcher. Krathwohl (2009) claimed that gaining entry and securing acceptance as the researcher can be some of the most difficult tasks for a researcher. This can be even more difficult when attempting to conduct a study at a public school, with underage children, and miles of district and parental red tape. Choosing myself to be teacher as researcher, I eliminated the notion of gaining entry and securing acceptance, as I was already a trusted and approved member of the licensed staff at Eagle High School, and I had built relationships with the students, the staff, the administration, and the parents.

Krathwohl (2009) and Merriam (2009) also argued that when using a specific tool or program in a study, one must defend credibility and reliability of the person using that tool. The tool that I used in my study is the Socratic Method. I am one of the few teachers 
at my high school that is trained and practiced in the art of Socratic questioning. I have four certificates of trainings in the Socratic Method; I employ and embed Socratic questioning and dialogue into my curriculum, and I have been consistent in using Socratic questioning and student dialogue in my classroom for the last 7 years.

\section{Data Sources and Collection}

I used basic qualitative methods to understand, examine, and discover the complex issue of how students make sense of Socratic questioning and their writing experiences. Data from basic qualitative studies are generally derived from interviews, observations, and document analysis (Merriam, 2009). My first step in data collection was making sure that I triangulated my data. This reduced the risk that my conclusions reflected only the systemic biases or limitations of a specific source or method, and allowed myself to gain a broader and more secure understanding of the issues I was investigating (Maxwell, 2005). Triangulating my data addressed validity threats that are very common in qualitative studies. Therefore, in order to triangulate my data I collected several types of data.

\section{Overview of Sources}

This study took place within a 6-week unit on persuasive writing techniques. Each week students participated in one mini lesson, one writing activity, and one Socratic questioning session about persuasive writing techniques that address ideas, organization, and conventions. For the purposes of this study, there were three data sources: (a) six Socratic questioning sessions with the 10 student participants were audio-recorded and then transcribed, (b) one one-hour interview with each student participant after the unit 
was over, and (c) Reflection Surveys from each student participant. This reflection sheet was given once before the unit began and once after the unit ended.

Six Socratic questioning sessions: Audio-recording and transcriptions. My

first data source was six Socratic questioning sessions that focused on persuasive writing techniques and emphasized ideas and content, organization, and conventions. For these data sources, there were transcriptions of the audio-recordings from the six Socratic questioning sessions.

Format for Socratic questioning sessions. The following is the format I used to conduct the six Socratic questioning sessions:

1. Ten purposefully selected students sat in a circle together.

2. As "unconcealed participant observer" and teacher as researcher, I began and lead the discussions with a list of pre-made Socratic questions about their writing.

3. Students engaged in discussion, used their own writing and the state rubrics as evidence for their claims and suggestions, and proposed their own questions and concerns to the group.

4. Each session lasted 25 minutes.

5. Each session was audio-recorded.

Questions for Socratic questioning sessions. According to many experts, there should be three levels of questioning during Socratic questioning: literal, inferential, and evaluative (Paul et al., 1997). The following questions were sample open-ended springboards for the six Socratic questioning sessions:

Literal:

- What can you tell me about your writing?

- How did you develop your claims? 
- How did you organize your essay?

- What types of punctuation did you use?

- What types of sentences did you use?

- How would this score on the rubric?

- Are you a confident writer?

Inferential:

- Why did you organize your essay that way?

- Which one is more persuasive and why?

- Why did you use those types of punctuation and not others?

- What do you mean by "better" or "bad" writing?

- Why did it get that score on the rubric?

- Why are you/ are you not a confident writer?

Evaluative:

- Can you organize your essay in other ways? If so, what?

- What other kinds of punctuation could have been used in your writing and how?

- What other kinds of sentences could have been used in your writing and how?

- How could this piece of writing have received a higher score on the rubric?

- How can you be more persuasive when you write?

- What can you do to be more confident when you write?

Audio-recording and transcriptions of Socratic questioning sessions. I used audio-recordings of Socratic questioning sessions because of the laws and restrictions that my school district had on videotaping our students. Audio-recordings captured the same truths and data as video recordings, and they allowed me more choice in my student selection. Using video recordings would limit the students that I could use for this study. 
There were many restrictions with student confidentiality in my school and district. I was not allowed to video tape or capture students' faces on picture.

The data from this source was different from my other data sources, the reflection surveys and the interviews, because the data obtained from the six sessions in Socratic questioning was socially constructed. Students had an opportunity to share experiences, tell stories, expand ideas, create theories together, and ultimately use each other to expand their own critical thinking about the topic. It also allowed me as the researcher to draw out inferences that I could not obtain by solely relying on interview data. This method not only directly connected back to the ideas of social constructivism and Socratic questioning presented in my conceptual framework, but it also addressed many of the goals and questions I had for this study.

One of the major tenets of social constructivism is that learners are multidimensional unique individuals, with unique backgrounds, unique needs, and unique beliefs (Fosnot, 1996; Phillips, 1995). The background and complexity of the individual is encouraged, celebrated, and used as an integral part of the learning process. The uniqueness of the learner colors the knowledge and truth that the learner creates in the process of learning (Ernest, 1994). Therefore, using data collected from six Socratic questioning sessions was a vital data source for this study, because it allowed the students to share, disclose, negotiate, and address previous assumptions and experiences socially.

One-on-one interviews. Because it is difficult to observe the processes and experiences of writing and improving one's own writing, my second data source was a single one hour interview with each of the 10 student participants after they had 
participated in six Socratic questioning sessions. Interviewing is an efficient and valid way of understanding participant perspective (Maxwell, 2005). Using interviews as one of my data sources, I was able to tie my goals, questions, and methods together more tightly. Interviewing students after they had participated in Socratic questioning allowed me to uncover and understand the participants' perspective on their experiences with Socratic questioning and their own writing.

Since my participants defined their participation in Socratic questioning and writing experiences in different ways, I did not use a highly structured interview; I used a semi-structured interview. Although I desired specific information from my participants, I predetermined a set of open-ended questions that would be flexible and easily lend to exploration of my topic. The goal of a semi-structured interview was to learn something about the phenomena of interest (Maxwell, 2005). Questions were formed in the general sense; there was no predetermined wording or order of questions for these interviews, as it was more like a conversation. The following questions were sample interview questions and are in no specific order. It is important to remember that before the interviews began, students were reminded of what Socratic questioning is and when they were asked to participate in it during the unit of study:

- What can you tell me about your writing?

- In what areas do you feel like you have improved?

- How did talking with your peers impact your writing?

- Did you learn something from your peers during any of the six sessions?

- What did you learn about writing or your own writing?

- Tell a story about a time you felt like you had improved in your writing. 
- Describe some instructional tools your teachers have used for writing instruction.

- Have those instructional tools been helpful and how?

- How can discussion about writing help a student improve their skills in ideas and content, organization, and conventions?

- How can Socratic questioning about writing help students?

- Did Socratic questioning impact you as a writer?

Reflection surveys. My third data source was Reflection Surveys. Each student completed a short answer reflection sheet that focused on traits of their own personal writing. By addressing strengths and weaknesses in these reflection sheets, students were able to pinpoint what roadblocks they experienced in writing and what helped them overcome those roadblocks. Since I gave this reflection sheet before and after the unit, I was able to identify changes in how students helped themselves and each other to become more effective writers. These reflection sheets were anonymous. This created some difference from the one-on-one interviews. These anonymous reflection sheets, when compared to one-on-one interviews, allowed students to be more honest and candid about their writing processes, failures, successes, and tools.

Questions for pre and reflection surveys. The following questions appeared on the Reflection Survey. Each student had an hour to fill out this short answer reflection sheet before the unit and after the unit.

- Do you feel you are a good writer? Why or why not?

- What strategies have helped you become a better writer?

- How did Socratic questioning can help you?

- Do you think Socratic questioning is a good tool for teachers to use when giving writing instruction? Why or why not?

- What do you do when you get writer's block? Does that work for you? 
- Do you think your peers can help you become a better writer? How?

- How can you help your peers become better writers?

- In the box below, draw what you think a writer looks like, then below the box, write a few sentences to describe your writer.

\section{Validity and Reliability}

Data cannot speak for itself, and it must be checked and crosschecked to ensure validity (Maxwell, 2005). As a researcher, I must ask myself: how might I be wrong? Does my evidence mirror reality? Do others see what I see? Using several tools and methods to address these concerns will bring dependability, credibility and validity to my study.

To address my own validity tests, I conducted intensive interviews as well as invited respondent validation. Intensive interviews enabled me to collect "rich" data that was detailed and varied enough to provide revealing conclusions about my topic (Maxwell, 2005). Audiotaping and transcribing all one-on-one interviews as well as the Socratic questioning sessions provided a detailed and descriptive transcription of what occurred during all conversations.

I enlisted respondent validation as "member checks" during the course of my study. To address possible misinterpretations and researcher bias of data, I solicited feedback from my participants. After each set of significant coding, I presented my finding to my participants. This ensured that their understanding of my transcriptions and my findings were aligning with my own. Thus, participant feedback was considered in part as evidence for validity to findings in this study. 
There are many strategies a qualitative researcher can use to strengthen issues that surround reliability. In order to ensure reliability and consistency in coding, I gave a portion of my transcriptions to another researcher. My co-worker, who is also a doctoral student and a qualitative researcher, was given a section of my transcriptions. She used the same coding method to come up with her findings. We compared our results for similarities and discrepancies. When discrepancies occurred, we discussed and agreed on the best code for that situation. Replicability is a valid concern; results of data analysis were consistent with the data collected.

\section{Classroom Details}

\section{Description of Class Period}

My fourth period English class is a Senior English class that starts at 11:30 am and is 51 minutes long. It is important to note that our school has three different lunch periods, so that we can spread out cafeteria capacity during lunchtime. This means that some students in my fourth period class have eaten lunch by this time every day, and some students will have lunch after this class period. There are 40 students: 22 male and 18 female. Despite there being 40 students, on any given day there are usually about four to five absences. There are 6 students with IEPs, 4 students who are in our English Language Development (ELD) program, 31 students on free and reduced lunch, 11 students who have not passed the Smarter Balanced Assessment Consortium (SBAC) writing test, 5 students who have not passed the SBAC reading test, 6 students who are in an additional Academic Support class for reading, 1 student who is on a behavioral 504 plan, and 1 student who is on a modified diploma. 


\section{Description of Student Participants}

For the purposes of this study, I used 10 students as participants. The following sections include descriptions of each student's GPA, personality, ethnicity, extracurricular activities, future goals, and home life.

Student participant \#1. Student participant \#1 is a 17-year-old, white, male senior. He is an involved student who is on the water polo team, the vice president of the Associated Student Body (ASB), and an overall social butterfly. He has a 3.6 GPA and hopes to go to a 4-year college when he graduates. As an avid member of the ASB, he in charge of many student activities and assemblies. He provides a unique and outgoing voice to our discussions, but he is prone to missing class due to ASB related activities. $\mathrm{He}$ is on free and reduced lunch and lives with his father. His mother passed away when he was 6 years old when giving birth to a second child.

Student participant \#2. Student participant \#2 is a 17-year-old, Hispanic, female senior. She is a member of the MEChA (Movimiento Estudiantil Chicanco de Aztlán) Club at our high school. Her family is from Mexico, but she has lived in the Unites States her whole life. Spanish is the primary language spoken at home. She lives with both her parents and two younger brothers. She is often at home taking care of her brothers while both parents work two jobs. She has a 3.2 GPA, is on free and reduced lunch, and she plans to go to community college when she graduates.

Student participant \#3. Student participant \#3 is an 18-year-old, white, female senior. She works at the local Dairy Queen to support herself and help her host family. Her father was incarcerated when she was a little girl, and her mother died of cancer over 
the summer. She currently lives with another senior student whose family has graciously taken her in, so that she could finish her senior year in district. She has a 3.0 GPA and does not participate in after school activities. She provides a very unique perspective to our discussions. She is on free and reduced lunch and has no plans for college after she graduates from high school.

Student participant \#4. Student participant \#4 is an 18-year-old, Russian, male senior. Born and raised in Russia, he moved to the United States when he was in eighth grade. He was an ELD student who worked his way through and out of our ELD program. He is not on free and reduced lunch and has a 2.8 GPA. He does not work, nor does he participate in after school activities. He is generally a shy and quiet student, but he has a lot of friends in the class, so he tends to be outspoken when grouped with his friends.

Student participant \#5. Student participant \#5 is an 18-year-old, white, female senior. She is on the varsity soccer team, the varsity track team, and works on weekends at her grandmother's dry cleaning business. She is in the foster care system and has moved from family to family three times in the last 5 years. She is very involved in after school sports but is also highly motived to do well academically. She has a 4.0 GPA and is one of the top honors students at our school. She takes many advanced and AP courses. She was in honors English the past 3 years but did not want to take AP Literature in her senior year. She is on free and reduced lunch and hopes to go to a 4-year college when she graduates. 
Student participant \#6. Student participant \#6 is an 18-year-old, black, female, senior. She is an only child and lives with both her parents. She is not on free and reduced lunch, and she currently has a 3.8 GPA. She works 20 hours a week at the garden center in Gresham. She wants to be a nurse, and she plans on going to Community College after she graduates.

Student participant \#7. Student participant \#7 is an 18-year-old, Asian, male senior. He lives with his mother and his grandmother. Both his father and grandfather live in Vietnam. He travels to Vietnam every summer to be with his father. He is not on free and reduced lunch, has a 3.9 GPA, and is a member of the National Honors Society. Although very quiet, he is a very talented piano player and plays for our school choirs. He hopes to go to a 4-year college when he graduates.

Student participant \#8. Student participant \#8 is a 17-year-old, white, male senior. He is on free and reduced lunch, lives with both his parents and an older sister, and has a 3.6 GPA. He has a 504 plan that allows him extra time on his written assignments. He rarely chooses to use the extra time but does advocate for himself when he feels necessary. He works at the coffee shop and tends to have many unexcused absences from class. He is very friendly to everyone in class and sits with his girlfriend, who is also in the same class.

Student participant \#9. Student participant \#9 is a 17-year-old, white, male senior. He is on free and reduced lunch and lives with both parents, his little sister, and his grandmother. He has a 3.2 GPA and is on the Varsity Football team at our school. Although he does not like playing football, his parents urged him to stay on the team for 
his final year of high school. He has many friends in class but is generally a very quiet student. He also has a 504 plan that allows him preferential seating and allows him to leave class for the restroom whenever he needs to. He hopes to go to Community College when he graduates from high school.

Student participant \#10. Student participant \#10 is an 18-year-old, Syrian, female senior. She is a 4.0 student who is on free and reduced lunch. She is highly motived to do well academically, and she is currently in five AP classes at our school.

She does not work or take part in after school activities at school. However, she is an avid member of the local Syrian community and her church. She is very outspoken in class, demands respect from her peers, and hopes to go to a 4-year college when she graduates.

Table 1 helps identify the gender, GPA, and race/ethnicity of each student participant that was randomly chosen for this study.

Table 1

Student Participant Information: Gender, GPA, Race/Ethnicity

\begin{tabular}{|l|l|l|l|}
\hline Student & Gender & GPA & Race/Ethnicity \\
\hline 1 & Male & 3.6 & White \\
\hline 2 & Female & 3.2 & Hispanic \\
\hline 3 & Female & 3.0 & White \\
\hline 4 & Male & 2.8 & Russian \\
\hline 5 & Female & 4.0 & White \\
\hline 6 & Female & 3.8 & Black \\
\hline 7 & Male & 3.9 & Asian \\
\hline 8 & Male & 3.6 & White \\
\hline 9 & Male & 3.2 & White \\
\hline 10 & Female & 4.0 & Syrian \\
\hline
\end{tabular}




\section{Description of Unit: What Happened in Class Before the Unit of Study?}

The unit of lessons that encompass this study was a 6-week unit on persuasive writing techniques with an emphasis on Socratic questioning. This was the second unit of the year, and it started on October 16 and ended on November 28.

During the first 2 weeks of school, students were introduced to classroom norms, classroom routines, and their classmates. For example, within the first few weeks of school, students learned to be on time and come to class prepared with materials. They learned that we start every class period with a Quick Write, and we end every class period with a Quick Talk. Quick Writes and Quick Talks are simple ways to check in about what happened yesterday in class and what we learned today in class. As part of our start-of-the-year routines, students have met all their classmates during the many "getting to know you" activities we did on the first days of school, and they have built stronger connections with their classmates since then.

In the first few weeks of school, we spent a significant amount of time building a culture of community during our "circle time" that we have once every 2 weeks. During circle time, students sit in a circle and a non-academic topic of discussion is brought to the group. An example question is: What is an event in your life that you regret? We go around in a circle and share how we feel and what we think about that topic. Students can pass from sharing if they want to, but this is a rare occurrence. This circle time allows students to hear what their peers think and believe, it gives them a safe space to speak about their own beliefs, and it creates a sense of community within the classroom. 
In the first unit of the year, we focused heavily on reading American Literature and analyzing author's choices for character, structure, and point of view, while staying grounded in Common Core $12^{\text {th }}$ Grade Reading Literature standards and Common Core $12^{\text {th }}$ Grade Speaking and Listening standards. During this unit, students in my class were introduced to and participated in three Socratic questioning sessions. During these sessions, we went over discussion norms and discussion techniques, while focusing our Socratic questions around the American Dream and how the authors we read supported or deviated from the American Dream. Thus, before the unit of study was used for the purposes of this research study, students became comfortable with class norms, their classmates, discussion techniques, and Socratic questioning.

Table 2 is a calendar that identifies what activities, standards, and objectives were addressed every day during the unit of study.

Table 2

Unit Calendar

\section{Unit 2 Context and Calendar}

Common Core Curriculum Standards:

Writing: ELACC11-12

W1a: Introduce precise, knowledgeable claim(s), establish the significance of the claim(s), distinguish the claim(s) from alternate or opposing claims, and create an organization that logically sequences claim(s), counterclaims, reasons, and evidence. W1b: Develop claim(s) and counterclaims fairly and thoroughly, supplying the most relevant evidence for each while pointing out the strengths and limitations of both in a manner that anticipates the audience's knowledge level, concerns, values, and possible biases.

W1c: Use words, phrases, and clauses as well as varied syntax to link the major sections of the text, create cohesion, and clarify the relationships between claim(s) and reasons, between reasons and evidence, and between claim(s) and counterclaims. 


\section{Table 2 (continued)}

Reading: ELACC11-12

RI3: Analyze a complex set of ideas or sequence of events and explain how specific individuals, ideas, or events interact and develop over the course of the text.

RI6: Determine an author's point of view or purpose in a text in which the rhetoric is particularly effective, analyzing how style and content contribute to the power, persuasiveness or beauty of the text. RI10: By the end of grade 12, read and comprehend literary nonfiction at the high end of the grades 11CCR text complexity band independently and proficiently

Speaking and Listening: ELACC11-12

SL1a: Come to discussions prepared; having read and researched material under study; explicitly draw on that preparation by referring to evidence from texts and other research on the topic or issue to stimulate a thoughtful, well-reasoned exchange of ideas.

SL1b: Work with peers to promote civil, democratic discussions and decision-making, set clear goals and deadlines, and establish individual roles as needed.

SL1c: Propel conversations by posing and responding to questions that probe reasoning and evidence; ensure a hearing for a full range of positions on a topic or issue; clarify, verify, or challenge ideas and conclusions; and promote divergent and creative perspectives.

\section{Learning Targets:}

Writing: Students will write and organize arguments to support claims and counter claims in an analysis of substantive topics or texts, while using valid reasoning, relevant and sufficient evidence, and a formal tone with command of basic conventions.

Reading: Students will read informational texts at the $11-12^{\text {th }}$ grade level. Students will analyze a complex set of ideas presented in the text, draw inferences, and examine the author's purpose and meaning.

Speaking and Listening: Students will initiate and participate effectively in a range of collaborative discussions with diverse partners on grades 11-12 topics, texts, and issues, building on others' ideas and express their own beliefs clearly and persuasively.

Student Goals:

I will write an argumentative essay with a claim and counter claim.

I will support my claims with evidence and analysis.

I will organize my ideas to be effective and persuasive.

I will make inferences and examine the author's purpose of an informational article.

I will work and discuss with my peers to share and listen to different perspectives and to develop ideas.

Student Vocabulary Targets:

Claim(c)/ Counter Claim(cc)/ Purpose

Effective Organization

Socratic Questioning 


\section{Table 2 (continued)}

\begin{tabular}{|c|c|c|c|c|}
\hline $\begin{array}{l}\text { Week Or } \\
\text { Monday }\end{array}$ & $\frac{\text { uction to } \mathrm{u}}{\text { Tuesday }}$ & Wednesday & Thursday & Friday \\
\hline & & $\begin{array}{l}\text { Pre-Assessment: } \\
\text { SBAC approved } \\
\text { argumentative } \\
\text { prompt. Student } \\
\text { given time to write } \\
\text { essays in class. }\end{array}$ & $\begin{array}{l}\text { 1. Intro to unit: } \\
\text { standards, targets, } \\
\text { goals, vocab } \\
\text { 2. Meet Discussion } \\
\text { Groups. "Get to } \\
\text { know you" } \\
\text { activities in } \\
\text { Groups. } \\
\text { 3. Pre Unit } \\
\text { Reflection Survey }\end{array}$ & $\begin{array}{l}\text { 1. Basic essay } \\
\text { notes: hook, thesis, } \\
\text { claim paragraph, } \\
\text { counter claim } \\
\text { paragraph, } \\
\text { conclusion. } \\
\text { 2. Basic paragraph } \\
\text { notes: topic } \\
\text { sentence, } \\
\text { evidence, analysis } \\
\text { 3. School } \\
\text { Assembly }\end{array}$ \\
\hline
\end{tabular}

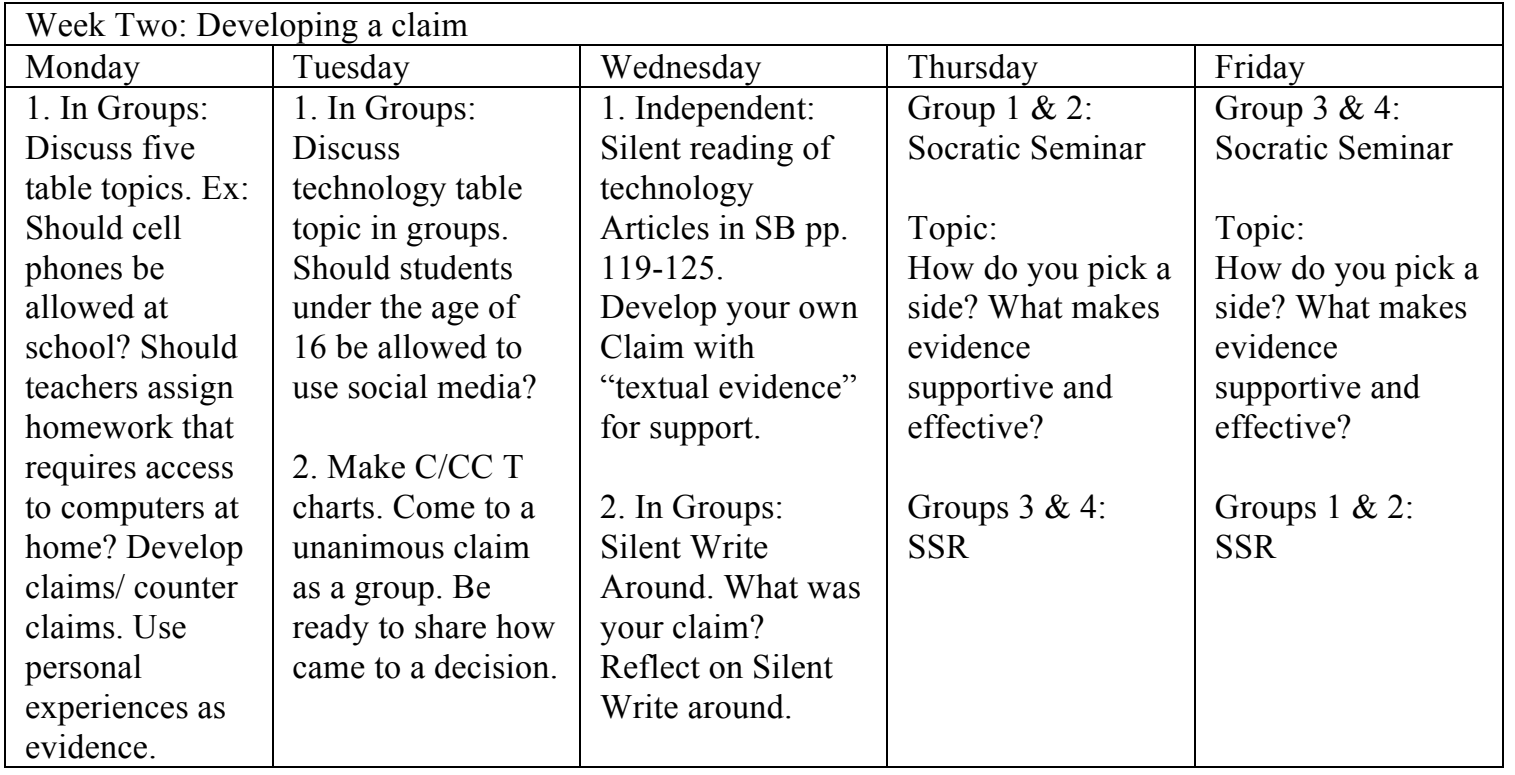


Table 2 (continued)

\begin{tabular}{|c|c|c|c|c|}
\hline \multicolumn{5}{|c|}{ Week Three: Organizing an argument } \\
\hline Monday & Tuesday & Wednesday & Thursday & Friday \\
\hline $\begin{array}{l}\text { 1. Independent: } \\
\text { Read } 2 \text { "Fast } \\
\text { Food Industry" } \\
\text { informational } \\
\text { articles in SB } \\
\text { pages 126-129. } \\
\text { 2. In Groups: } \\
\text { Complete } \\
\text { thesis, } \\
\text { summary, and } \\
\text { purpose } \\
\text { activity. } \\
\text { 3. Independent: } \\
\text { Use group } \\
\text { thesis. Write an } \\
\text { essay outline to } \\
\text { organize C and } \\
\text { CC ideas. }\end{array}$ & $\begin{array}{l}\text { 1. Mini Lesson: } \\
\text { Basics to } \\
\text { Organizing an } \\
\text { essay. Notes and } \\
\text { jigsaw activity. } \\
\text { Group } 3 \text { \& 4: SSR } \\
\text { Group } 1 \text { \& 2: } \\
\text { Socratic Seminar } \\
\text { Topic: Share } \\
\text { outlines. } \\
\text { Discuss how each } \\
\text { person organized } \\
\text { thoughts and why. } \\
\text { How does that } \\
\text { compare to class } \\
\text { notes? Which is } \\
\text { better? Why? }\end{array}$ & $\begin{array}{l}\text { Group } 1 \text { \& 2: SSR } \\
\text { Group } 3 \text { \& 4: } \\
\text { Socratic Seminar } \\
\text { Topic: Share } \\
\text { outlines. } \\
\text { Discuss how each } \\
\text { person organized } \\
\text { thoughts and why. } \\
\text { How does that } \\
\text { compare to class } \\
\text { notes? Which is } \\
\text { better? Why? }\end{array}$ & $\begin{array}{l}\text { 1. Independent: } \\
\text { Read } 4 \text { "Apathy } \\
\text { and Teen" } \\
\text { informational } \\
\text { articles in SB 144- } \\
156 . \\
\text { 2. Choose a side to } \\
\text { this topic. Write an } \\
\text { argumentative } \\
\text { essay. Use textual } \\
\text { evidence from } \\
\text { articles to support } \\
\text { your claim and } \\
\text { counter claim. }\end{array}$ & $\begin{array}{l}\text { Finish writing } \\
\text { Essay. SSR when } \\
\text { done. }\end{array}$ \\
\hline
\end{tabular}

\begin{tabular}{|c|c|c|c|c|}
\hline \multicolumn{5}{|c|}{ Week Four: Rubrics } \\
\hline Monday & Tuesday & Wednesday & Thursday & Friday \\
\hline $\begin{array}{l}\text { 1. In groups: } \\
\text { choose group } \\
\text { roles: } \\
\text { Facilitator, } \\
\text { timer, gate } \\
\text { keeper, } \\
\text { recorder, etc. }\end{array}$ & $\begin{array}{l}\text { 1. In Groups: Read } \\
\text { over SBAC } \\
\text { writing Rubric. } \\
\text { Discuss main } \\
\text { points of Rubric, } \\
\text { major things to } \\
\text { look for, etc. }\end{array}$ & $\begin{array}{l}\text { Independent: } \\
\text { Rewrite essays. } \\
\text { Using both group } \\
\text { and SBAC rubrics } \\
\text { as guide to } \\
\text { improve from your } \\
\text { original score. }\end{array}$ & $\begin{array}{l}\text { Half day for } \\
\text { students. Report } \\
\text { Card prep for } \\
\text { teacher. } \\
\text { All groups: SSR }\end{array}$ & $\begin{array}{l}\text { All School Career } \\
\text { Day. } \\
\text { No class } \\
\text { instruction. }\end{array}$ \\
\hline $\begin{array}{l}\text { 2. All groups: } \\
\text { Student Driven } \\
\text { Socratic } \\
\text { Seminar: } \\
\text { How should an } \\
\text { essay be } \\
\text { graded? Create } \\
\text { Group Rubric. } \\
\text { Defend } \\
\text { categories, } \\
\text { strengths, } \\
\text { weaknesses. } \\
\text { Score your own } \\
\text { paper using } \\
\text { group Rubric. }\end{array}$ & $\begin{array}{l}\text { 2. Score your own } \\
\text { paper with SBAC } \\
\text { rubric. Score } \\
\text { essays in your } \\
\text { groups. } \\
\text { 3. Discuss with } \\
\text { groups why each } \\
\text { grade was given. }\end{array}$ & $\begin{array}{l}\text { Turn in essay as } \\
\text { formative } \\
\text { assessment. }\end{array}$ & & \\
\hline
\end{tabular}


Table 2 (continued)

\begin{tabular}{|c|c|c|c|c|}
\hline \multicolumn{5}{|c|}{ Week Five: Command of Conventions } \\
\hline Monday & Tuesday & Wednesday & Thursday & Friday \\
\hline $\begin{array}{l}\text { 1. In groups: } \\
\text { choose group } \\
\text { roles: } \\
\text { Facilitator, } \\
\text { timer, gate } \\
\text { keeper, reader, } \\
\text { recorder, etc. } \\
\text { 2. All groups: } \\
\text { Student Driven } \\
\text { Socratic } \\
\text { Seminar: } \\
\text { Topic: } \\
\text { Why } \\
\text { conventions are } \\
\text { important? } \\
\text { What } \\
\text { conventions to } \\
\text { use when? } \\
\text { Why? }\end{array}$ & $\begin{array}{l}\text { In groups choose } \\
\text { group roles: } \\
\text { Facilitator, timer, } \\
\text { gate keeper, } \\
\text { reader, recorder, } \\
\text { etc. } \\
\text { All groups: } \\
\text { Student Driven } \\
\text { Socratic Seminar: } \\
\text { Topic: } \\
\text { Read } 2 \text { different } \\
\text { news articles. Pay } \\
\text { close attention to } \\
\text { conventions used. } \\
\text { Was it effective? } \\
\text { Why that piece of } \\
\text { punctuation? }\end{array}$ & $\begin{array}{l}\text { Independent: } \\
\text { Read Op-Ed } \\
\text { articles SB pages } \\
\text { 155-160. } \\
\text { Mini Lesson: } \\
\text { semi-colons, } \\
\text { colons, and } \\
\text { complex } \\
\text { sentences. } \\
\text { With a partner: } \\
\text { write an op-ed } \\
\text { piece about the } \\
\text { table topic. Use } \\
\text { semi-colons, } \\
\text { colons, and } \\
\text { complex } \\
\text { sentences. }\end{array}$ & $\begin{array}{l}\text { SBAC approved } \\
\text { argumentative } \\
\text { prompt given. } \\
\text { Each student will } \\
\text { write an } \\
\text { argumentative } \\
\text { essay using } \\
\text { personal } \\
\text { experience as } \\
\text { evidence for } \\
\text { support of claims } \\
\text { and counter } \\
\text { claims. }\end{array}$ & $\begin{array}{l}\text { Finish essays. } \\
\text { Turn in essays for } \\
\text { formative } \\
\text { assessment. } \\
\text { SSR when done. }\end{array}$ \\
\hline
\end{tabular}

\begin{tabular}{|c|c|c|c|c|}
\hline \multicolumn{5}{|c|}{ Week six: "Good" and "Bad" Writing } \\
\hline Monday & Tuesday & Wednesday & Thursday & Friday \\
\hline $\begin{array}{l}\text { Conference } \\
\text { with Ms. H } \\
\text { about essay } \\
\text { score. } \\
\text { SSR while not } \\
\text { conferencing. }\end{array}$ & $\begin{array}{l}\text { Independent: } \\
\text { Read SBAC } \\
\text { argumentative } \\
\text { essays that } \\
\text { received high } \\
\text { scores. } \\
\text { In Groups: } \\
\text { Silent Write: what } \\
\text { does good writing } \\
\text { look like? } \\
\text { Reflection of } \\
\text { Silent Write }\end{array}$ & $\begin{array}{l}\text { Independent: } \\
\text { Read } 4 \\
\text { "Democratic } \\
\text { Society" } \\
\text { informational } \\
\text { articles in SB 162- } \\
171 . \\
\text { Choose a side to } \\
\text { this topic. Write an } \\
\text { argumentative } \\
\text { essay. Use textual } \\
\text { evidence from } \\
\text { articles to support } \\
\text { your claim. }\end{array}$ & $\begin{array}{l}\text { Finish Essays. } \\
\text { SSR when done. } \\
\text { Turn in Essay for } \\
\text { Summative } \\
\text { Assessment. }\end{array}$ & $\begin{array}{l}\text { Independent: } \\
\text { Post Unit Survey } \\
\text { In groups: } \\
\text { All groups: } \\
\text { Last Socratic } \\
\text { Seminar } \\
\text { Topic: The writing } \\
\text { process, Socratic } \\
\text { seminars, good vs } \\
\text { bad writing. }\end{array}$ \\
\hline
\end{tabular}


Table 2 (continued)

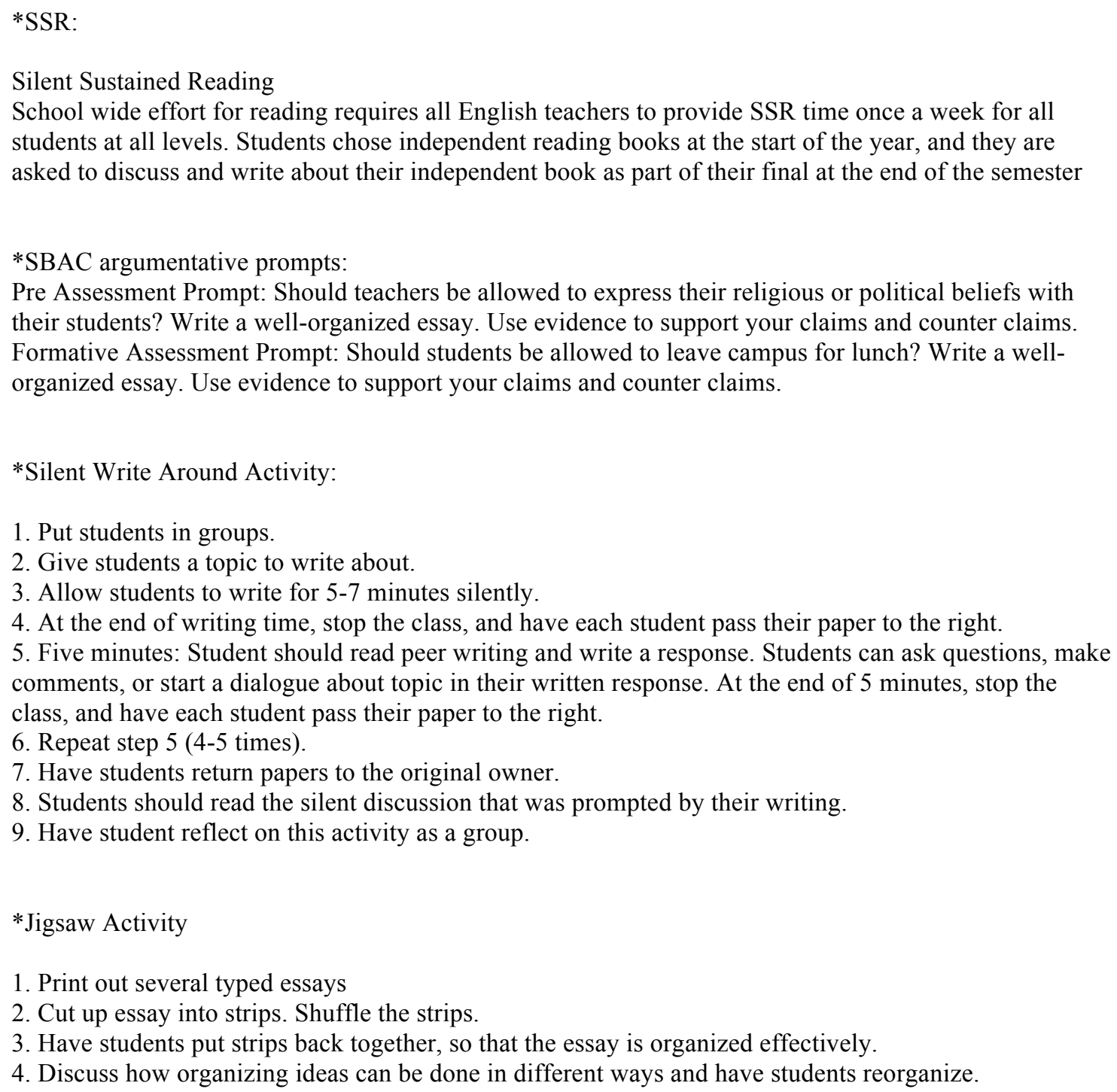

*Socratic questioning session topics

Table 3 identifies the topic of discussion for each Socratic questioning session. 


\section{Table 3}

\section{Socratic Questioning Session Topics}

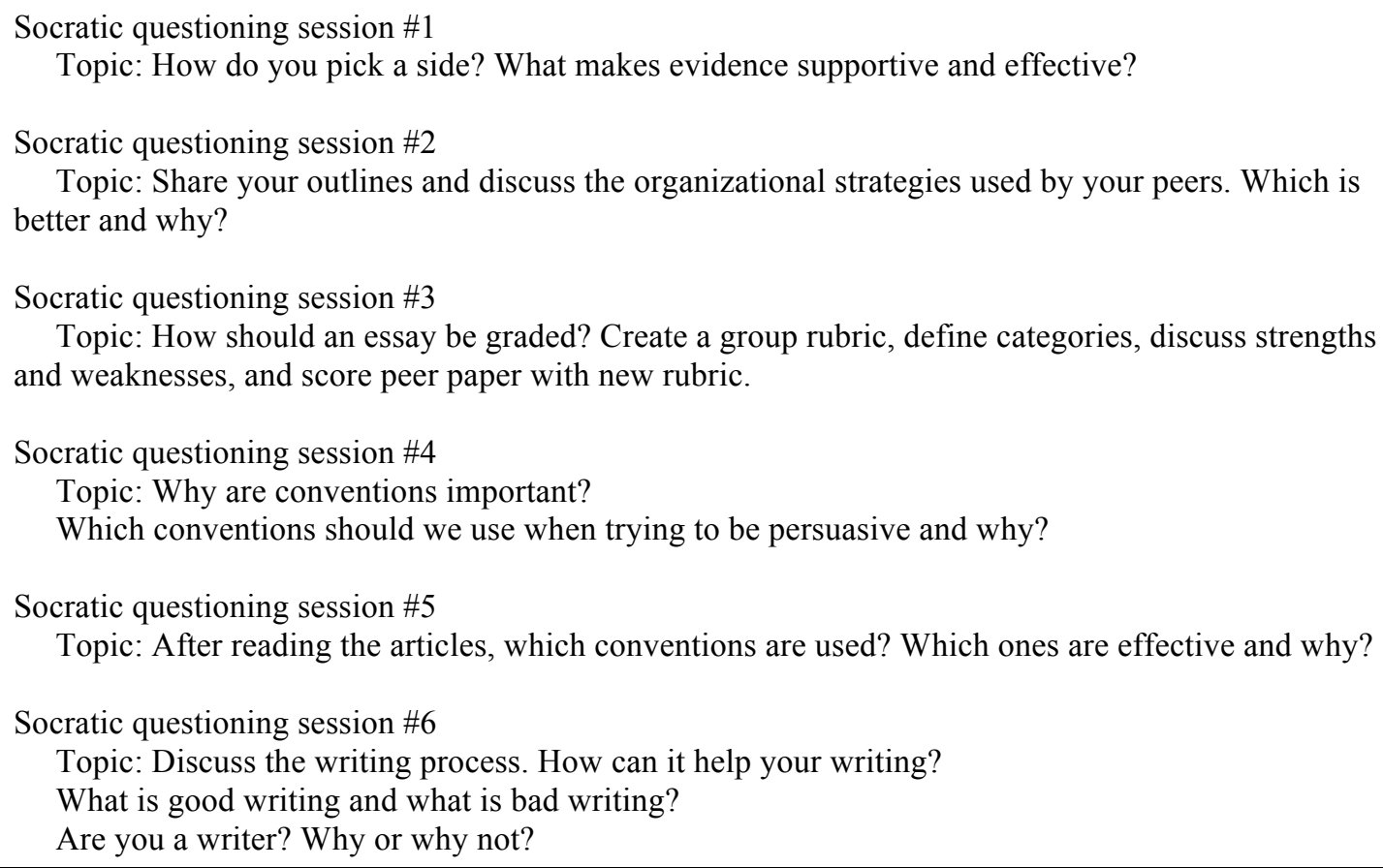

\section{Data Analysis Overview}

Qualitative data analysis is emergent and inductive. When using qualitative data, coding, organizing, and labeling of the data collected is an intuitive, flexible, and formative process. As a qualitative researcher, it can be difficult to determine the course of data analysis before beginning to collect data. However, there are many steps to organizing one's plan for a data analysis.

Since I had three very different data sources, I chose to code and analyze each data source differently. Data source \#1 was the Reflection Surveys. I read through each response for each question, combined like responses into categories, and noted outlying responses. I did the same with the post surveys, and concluded my analysis by comparing 
the categories from both surveys. This led me to an overall theme and theory that helped answer my research question. Data source \#2: transcriptions from the Socratic questioning sessions, and data source \#3: transcriptions from one-on-one interviews, were similar in data type, so I weaved both data sources through four rounds of coding. I will detail this coding process in the following sections. This coding process allowed me to develop categories, themes, and finally a theory that would help answer my research question. The following is a detailed description of the coding process used for all transcriptions from data source \#2 and data source \#3.

After transcribing the data from each Socratic questioning session and each interview, I put brackets around chunks of texts and I numbered the chunks, as I thought they would be valuable for later coding. Then, I began an initial coding process where I made notes for the bracketed text that I thought might be helpful in my next coding sessions. Being the judge of my data and identifying what I thought would be important helped remind me that starting the coding process is a judgment call; the researcher truly brings their own personality and subjectivities to the coding process.

After my initial notes, I narrowed down which coding process would be appropriate for my study. Saldana (2009) suggested that the following questions be asked: Is the codling method harmonizing with your study's conceptual framework? Is the coding method relating to your research questions? Is the coding method leading to an analytic pathway? Considering those questions, I decided to start my second cycle coding with Elemental Methods: Descriptive coding and In Vivo codes. Guided by my theoretical framework and working under notions of social constructivism, I hoped that 
Elemental Methods would steer me down a pathway concerned with student voice and action.

During Descriptive coding, I summarized already identified chunks of text with a short word or phrase. This was helpful in identifying the topic of conversation between the participants. During In Vivo coding, I was able to help root the meanings of my codes in the actual language found in the data (Saldana, 2009). Ultimately, In Vivo coding proved to be the most meaningful coding method, as it allowed me to stay true to the actual words my participants were using.

Although some may argue that In Vivo coding can limit the researcher's perspective, I ultimately wanted to preserve meaning from my data and capture true behavior and discussion from it. In Vivo coding features participant voice, and grasps what is significant to the speaker. In Vivo codes are participant inspired and essentially help crystallize and condense meaning (Saldana, 2009).

Saldana (2009) argued that Process coding is appropriate for virtually all qualitative studies, particularly for those that search for action, interaction, and emotion. Process coding uses gerunds to identify action. I would claim that this coding step was a preliminary action to my third cycle of coding. I wanted to narrow down and reorganize my In Vivo codes by giving those quotes an action.

Process coding was the staple of my third cycle of coding. It exemplified the complex interaction of factors that came into play when I examined how events and actions emerged, shifted, and evolved from their original meaning. Keeping in mind my research goals and questions, this process helped provide me a reanalysis of my initial 
coding work, while simultaneously staying true to the actual language used by my participants.

Third cycle coding is a more advanced way of reorganizing and reanalyzing the data that was coded during my first few cycles. The ultimate goal of second and third cycle of coding was to produce clarification of previously collected data, and to develop a sense of categorical, thematic, or theoretical organization from existing codes (Saldana, 2009).

Saldana (2009) argued that Pattern coding develops a "meta-code." After my Process codes, I was able to start recognizing patterns and categories. The Pattern coding process identifies similarly coded data to reorganize and attribute meaning to that organization, and therefore allows one to meta-code (Saldana, 2009).

Since Pattern codes are meant to be inferential and identify emerging themes or explanations (Saldana, 2009), I was able to pull together my Process codes and data linked to those codes, so that I could synthesize those codes into even more meaningful categories. This regrouping allowed me to create several categories and themes that eventually led me down a theoretical pathway.

Analysis of my collected data was ongoing. Once I transcribed a session of Socratic questioning or a single interview with one student, I put each new session and each new interview through the coding process I detailed above. Once I had coded each Socratic questioning session and each interview, I was able to compare the categories and Pattern codes from my first session to the next session. This comparison informed the next data collection and so on. This comparison constituted my fourth cycle of coding. I 
compared the patterns and categories that emerged from each discussion session. This helped me narrow down my categories and findings so that I could come up with a tentative theme. As the Socratic questioning sessions and the interviews carried on, I continued organizing, reorganizing, and refining my data into chunks, categories, and themes. Data collection was a simultaneous process with the study in time. The final product was shaped by the data that was collected and the analysis that accompanies the entire process. Consolidating, reducing, and interpreting, as well as moving back and forth between my data sources and my abstract themes and understandings, led me to being able to answer my research question. 


\section{CHAPTER FOUR}

\section{FINDINGS}

\section{Overview}

The purpose of this study was to investigate if Socratic questioning is an effective tool for improving student perception of the writing process. The major aim of this study was to understand what methods or strategies improve students' perceptions of writing and the writing process. Thus, one research question was posed to accomplish this purpose: How can Socratic questioning improve students' perceptions of writing and the writing process?

Three data sources were used to answer this research question: transcriptions of audio-recordings from six Socratic questioning sessions, transcriptions of audiorecordings from interviews with each of the 10 student participants after they participated in the Socratic questioning sessions, and pre and post Reflection Surveys collected from all 10 of the student participants.

Chapter 4 is divided into two major sections. In the first section, I include a model of what the coding process looked like for each data source. For my first data source, the Reflection Surveys, I sectioned out each question from the survey. Next I charted and analyzed the findings from each question. For my second data source, the transcriptions from the Socratic questioning sessions, I included several pieces of transcripts and illustrated how each chunk was weaved through my coding process. For my third data source, the one-on-one interviews, I again included several chunks of transcripts and 
illustrated how each chunk was weaved through my coding process. The second section of this chapter is divided into two subsections. These subsections feature the two major findings, conclusions, and discussion points that I drew from my study.

\section{Coding Model for Data Source \#1: Reflection Surveys}

After I collected my pre surveys, I consolidated responses by making initial notes, categorized similar responses, marked notable quotes, and noted outlying responses.

Once I collected post surveys, I was able to note and consolidate responses, categorize them, and compare pre and post responses.

\section{Survey Question \#1}

Do you feel you are a good writer? Why or why not?

In the pre survey, only 2 students saw themselves as good writers. Eight out of the 10 student participants described themselves as bad writers. "I don't think I'm good at it" and "I suck at writing" are two responses from this section. In the post survey, 10 out of the 10 student participants believed themselves to be good writers. They wrote: "I am not going to quit my day job, but I am a solid writer" and "Yes. I am a good writer, and I think I can do a good job writing about any topic." Table 4 indicates sample responses and comparisons from Reflection Survey question 1.

Table 4

Question 1 Sample Category Comparison

\begin{tabular}{|l|l|l|}
\hline Survey Category & Pre \# Responses & Post \# Responses \\
\hline See themselves as bad writers & 8 & 0 \\
\hline See themselves as good writers & 2 & 10 \\
\hline
\end{tabular}




\section{Survey Question \#2}

What strategies have helped you become a better writer?

In the pre survey, all students referred to adults and teachers in their past who helped them become better writers. The following are some of the responses from the pre survey: "Copying teacher notes on how to write," "Getting help from my mom and dad," and "Trying to remember what I learned from my last year's English teacher." The post survey responses reflected peer discussion. Students found that talking with their peers helped them become better writers. Some responses from the post survey include things such as "Talking to my peers," "Discussing what is good and bad," and "Socratic Seminars with my classmates." Table 5 indicates sample responses and comparisons from Reflection Survey question 2.

Table 5

Question 2 Sample Category Comparison

\begin{tabular}{|l|l|l|}
\hline Survey Category & Pre \# Responses & Post \# Responses \\
\hline Past Mentors/ Experiences & 10 & 0 \\
\hline Peers/Discussion with Peers & 0 & 10 \\
\hline
\end{tabular}

\section{Survey Question \# 3}

How did Socratic questioning help you?

In the pre survey most students said that Socratic questioning helped their independent learning process. For example, some students wrote: "Socratic questioning helps me understand what I am reading," "It helps me know what to focus on," "and I think it makes me think about deeper things that I wouldn't have thought about before." 
In the post survey, students were more concerned with group learning and group creation. For example some students wrote: "Socratic questioning helps me see what others are thinking," "Socratic questioning is helpful because I can tell my group what I was thinking and see if they were thinking the same thing too," "Socratic questioning helps me understand what other possibilities could be out there." Table 6 indicates sample responses and comparisons from Reflection Survey question 3.

Table 6

Question 3 Sample Category Comparison

\begin{tabular}{|l|l|l|}
\hline Survey Category & Pre \# Responses & Post \# Responses \\
\hline Independent Experiences & 10 & 2 \\
\hline Group/ Peer Experiences & 0 & 8 \\
\hline
\end{tabular}

\section{Survey Question \# 4}

Do you think Socratic questioning is a good tool for teachers to use when giving writing instruction? Why or why not?

In the pre survey, many students had a negative response, and they did not understand how Socratic questioning could help their writing. The following are some responses from the pre survey: "We have only used Socratic Seminars for when we read, I don't know what it would be like for when we write," "I want the teacher to just show what I am supposed to do, so that I can get a good grade," “No. I don't like talking in front of people." In the post survey, students were much more positive and had a better understanding of how they could use their peers to become better writers. For example, they wrote: "It is good because it helps me see that there are many different ways to 
write," "Yes because we are working together to make something better," "I still don't like to talk with people, but it shows me more ways to write." Table 7 indicates sample responses and comparisons from Reflection Survey question 4.

Table 7

Question 4 Sample Category Comparison

\begin{tabular}{|l|l|l|}
\hline Survey Category & Pre \# Responses & Post \# Responses \\
\hline Could not make connection & 7 & 1 \\
\hline Could make connection & 3 & 9 \\
\hline
\end{tabular}

\section{Survey Question \#5}

At what point do you usually get stuck when you write?

Student responses for this question were all different, but all students could identify where they get stuck when they write. The following are some responses from the pre survey: "Hooks," "Thesis," "Starting my paragraphs." In the post survey, a few students said that they do not get stuck anymore, but many students felt like they got stuck in the same places they used to get stuck. For example, students wrote: "I don't get stuck starting anymore, because I don't feel afraid to write anymore, but I do get stuck using the right words to analyze my evidence" and "Writing feels easier to me now, but I still get stuck thinking of my hooks." Table 8 indicates sample responses and comparisons from Reflection Survey question 5. 
Table 8

Question 5 Sample Category Comparison

\begin{tabular}{|l|l|l|}
\hline Survey Category & Pre \# Responses & Post \# Responses \\
\hline Identify areas of being stuck & 10 & 7 \\
\hline Do not get stuck anymore & 0 & 3 \\
\hline
\end{tabular}

\section{Survey Question \#6}

I took out this question. It was too similar to \#5, and students were very confused.

\section{Survey Question \#7}

What do you do when you get writer's block? Does that work for you?

In the pre survey all students had different responses, but their responses were centered around individual tools. For example, in the pre survey, students wrote: "I think harder," "I give up," and "I draw." In the post survey, all students considered tools that involved their peers and talking. They wrote: "I talk to my friends in class about what they wrote," "I look back to other things I did and my friends did and try to remind myself what I need to do," and "I ask my group and my teacher questions." Table 9 indicates sample responses and comparisons from Reflection Survey question 7.

\section{Table 9}

Question 7 Sample Category Comparison

\begin{tabular}{|l|l|l|}
\hline Survey Category & Pre \# Responses & Post \# Responses \\
\hline Individual Tools & 10 & 0 \\
\hline Group/Discussion/ Peer related Tools & 0 & 10 \\
\hline
\end{tabular}




\section{Survey Question \#8}

Do you think your peers can help you become a better writer? How?

In the pre survey, students said that writing was an independent activity and that it would be cheating if peers helped them write. They wrote: "Isn't writing supposed to be an alone activity" and "No. I'll get caught cheating if my friend helps me write my essays." In the post survey, all students agreed that their peers could help them in a variety of ways. They wrote: "Yeah! We can talk about what is good and bad and help each other come up with something better," "I can see what they wrote and I can see how to do things differently," and "Yes. I can talk to them and listen to their ideas." Table 10 indicates sample responses and comparisons from Reflection Survey question 8.

Table 10

Question 8 Sample Category Comparison

\begin{tabular}{|l|l|l|}
\hline Survey Category & Pre \# Responses & Post \# Responses \\
\hline Peers cannot help & 10 & 0 \\
\hline Peers can help & 0 & 10 \\
\hline
\end{tabular}

\section{Survey Question \#9}

I took out this question. It was too similar to \#8, and students got very confused.

\section{Survey Question \#10}

In the box below, draw what you think a writer looks like, then below the box, write a few sentences to describe your writer.

In the pre survey, two students left this box blank. Three students drew and titled a famous writer that we had read in the past unit: Fitzgerald, Whitman, etc. Five students 
drew someone with a pencil or pen in their hands. An interesting thing to note is that most of these drawings were stick figures. In the post survey, five students drew themselves, four students drew a group of people sitting in a circle, and one student again drew a famous writer that we had read in the past unit. One important difference to note in the post survey was that none of these drawings were stick figures. These drawings of writers were detailed, rounded, and clothed. Table 11 indicates sample responses and comparisons from Reflection Survey question 10.

Table 11

Question 10 Sample Category Comparison

\begin{tabular}{|l|l|l|}
\hline Survey Category & Pre \# Responses & Post \# Responses \\
\hline Stick Figures & 10 & 0 \\
\hline Famous Writer & 3 & 1 \\
\hline Nondescript Writer Alone & 5 & 0 \\
\hline Nondescript Writer in Group & 0 & 4 \\
\hline Themselves as Writer & 0 & 5 \\
\hline Blank & 2 & 0 \\
\hline
\end{tabular}

\section{Coding Model for Data Source \#2: Transcriptions of Socratic Questioning Sessions}

After transcribing the data from each Socratic questioning session, I began a precoding process where I put brackets around chunks of text and made initial notes. Then, I began my second cycle of coding with Elemental Methods: Descriptive coding and In Vivo codes. Next, Process coding and Pattern codes would be the staple to my third cycle of coding. Then I was able to synthesize those codes into even more meaningful 
categories. This regrouping allowed me to create several categories and themes that eventually led me down a theoretical pathway.

Analysis of my collected data was ongoing. Once I transcribed a Socratic questioning session, I would put each transcription through the process described above. Once I had more than one set of codes for each session, I was able to compare the first set of data with the second. This comparison of categories from each session established my fourth cycles of coding and it informed the next data collection and so on. This helped me narrow down my categories and findings so that I could come up with a tentative theme. As the Socratic questioning sessions carried on, I continued organizing, reorganizing, and refining my data into chunks, categories, and themes. These understandings led me to a theory that would help me answer my research question.

Table 12 identifies sample questions from each level of questioning from all six Socratic questioning sessions. In the next section, I will provide three models of analysis. Each model of analysis was taken from one of the three levels of questioning. I did this to demonstrate how the data were coded and how those codes are connected to each level of questioning from the Socratic questioning process. 
Table 12

Sample Socratic Questioning Questions

Sample Literal questions from each Socratic questioning Sessions:
What is the claim?
What is your outline?
How has your writing been graded in the past?
Which conventions were used in the article?
What conventions did your peer use?
How would you describe the writing process?
Are you a writer?
Sample Inferential questions from each Socratic questioning Session:
What makes an argument persuasive?
How can we use our evidence effectively?
Which organizational strategy is better and why?
Which rubric categories are more important than others?
Which conventions are more effective?
Why is the writing process important?
Sample Evaluative questions from each Socratic questioning Session:
How will you support your claim next time you write persuasively?
What is the best way to organize your paper?
Which conventions will you use when writing persuasively and why?
Next time you get a rubric, what elements will you look for?
How can you be a better writer?
What can you do to make the writing process work better for your needs?

\section{Data Source \#2: Model Analysis \#1}

The following is an excerpt from the transcript of Socratic questioning session \#2.

It is 6.21 minutes into the discussion. Here, students are discussing what it means to be persuasive and the best way to organize one's writing to be more persuasive. It is important to note that during this transcription, students are addressing questions from the evaluative level of questioning. The text chunks that I thought were important from this excerpt were chunks 17 and 18. I will be detailing my analysis process for chunk 17. Also, I included a continuing section of the transcript that was not marked for further 
coding, as well as chunk 18, to illustrate how parts of the transcripts were not valuable to my analysis but just how quickly other chunks became valuable and noteworthy.

\section{Socratic seminar text chunk \#17.}

Facilitator: Do you think it more persuasive to your readers if you address your claim before you address your counter claim? Why or why not?

Student 7: Yes. Cause it's good to tell the people what you think right away.

Student 9: Yeah. Mrs. Dap always told us to put our claim analysis first.

Student 8: Yeah.

Student10: Yeah. I remember her telling us that too.

Student 5: The article you had us read yesterday put their counter claim first.

Student 7: I guess it's just as good to tell them what you think at the end.

Student 5: I like it when they save their own thoughts for the end. Helps make it better.

*Silent pause in discussion

Facilitator: What do you mean by "better"?

Student 5: Well they told us what other people thought in the first few paragraphs, but then they ended the article by telling us why those people were wrong.

Student 9: It's better because they can counteract the other people and prove why those people are wrong.

Student 5: It's more persuasive that way. See Mrs. H. I remember what we talk about in class.

Students 4, 5, 10: Laughing

Facilitator: Well, I am glad you are talking about what is persuasive. So let's take it one more step. Why is it important to be persuasive?

Student 2: If you're trying to make a point, then you want people to take your side.

Student 5: If no one was persuasive, then when would anyone ever change their minds? 
*End Socratic Seminar Text Chunk \#17. Continued Transcript.

Student 2: Yeah like a lawyer and a jury.

Student 5: Like ... Tanantino.

Student 2: Like Darien Aronofsky.

Student 6: ummmm?? What?

Student 5: I feel like he's really persuasive with his movies, cause his characters are so real, and then I feel like he changes my mind about things.

Student 1: But if you wait till the end to tell everyone what you think, isn't that bad?

Student 3: Are you putting your Claim paragraph before your Counter Claim paragraph?

Student 1: No

*Silent Pause in discussion

Student 5: Yes

Student 3: Do you want people to know right away what you think?

Student 5: Don't you?

*Overhead announcement: Cal bus students. Please come to the front of the school. Your bus is waiting for you.

Student 1: God. Bella needs to recognize.

Student 7: ha ha

Student1: Seriously. She needs to hold the mic away from her face. Doesn't she know all her announcements are so annoying.

Student 5: Dude Bella is the best. And I just asked you a question. Raise your hand if you want people to know right away what you think? 


\section{Socratic seminar text chunk \#18.}

Student 1: Well it depends how well you can prove them wrong. It depends how you analyze the counter claim. If you can put some effort into analyzing their weaknesses, then maybe it is good if you wait till the end.

Student 9: Wait. Mrs. H. So you're saying Mrs. Dap is wrong?

Facilitator: Not necessarily. Part of the point of this discussion is for us to examine previous understandings. It doesn't mean that those old understandings are wrong. Your discussion mates have simply presented new ways of organizing their essays.

Student 9: So which one is the right way?

Student 6: Dude. That's not the point of this. There isn't a right or wrong. There's an old and new.

Student 9: So which way are you going to organize your essay?

Student 6: I don't know yet. I like what said about waiting to see how you can contradict the counter claim. I think I will put my Claim paragraph at the end.

Figure 1 illustrates my coding process and analysis of Text chunk \#17.

\section{Data Source \#2: Model Analysis 2}

The following is an excerpt from the transcript of Socratic questioning session \#5. It is 2.30 minutes into the discussion. This transcription is taking place during inferential level of questioning. Students were asked to share their own writing with a partner. They were asked to identify punctuation that their peer used and to discuss why the punctuation was used and why it is effective. The text chunk I found important from this section is Text Chunk \#49. 
Bracketed text \# 17 - SS Round 1:

Notes/ Jottings

- organizng Rersuastre essays - why is persuasion
- which way is "better"?

Round 2:

Descriptive Codes

- Reviewng chat thy were tanght in pastyears

- CC betore C to phave CC wkeny - point of persuasun is
In Vivo codes

In Vivo Codes
-IRemember her teunus" - "llke it wlen" "makes $1+$ bettes

- "Hs more persuasce trat way" "Wlen would aryone
Round 3: charge teir mirel

Process Codes
- Remembery past understandings - discussing dittent opt - changing people's minds - makingurting ketter

Pattern/Category Codes

- Past asumptim - persuasm I charge

- exposirg new ldeas - weighing nuw ideas

Round 4:

Compared Pattern/ Category Codes

- sharing cleas - creatry new ideas
- Evaluarty new ideas - usly now ideas

Themes

- Discussion can create change.

- sharing can lead to anaysis of old assumption

Figure 1. Model analysis text chunk \#17. 


\section{Socratic seminar text chunk \#49.}

Facilitator: Now that you have identified the punctuation you want to talk about in your peer's work, discuss why they used it and how it made their sentence more effective.

Student 2: Okay ... so you used a semi-colon in your thesis.

Student 5: Yeah, cuz, I wanted to make a point better

Student 2: the second sentence after the semi-colon is where you made your point better?

Student 5: Yeah, at first I just had a thesis sentence with this part-(student points to first part of the semi-colon sentence)

Student 2: Oh yeah okay. The second part makes it deeper.

Student 5: Yeah, cuz, if I left it without the semi-colon, then I couldn't make the point about students not understanding.

Student 2: So here's my thesis. How can I make it better?

Student 5: Well what point do you really wanna make past this sentence.

Student 2: Oh yeah okay. So I am going even further to make my point. So this first sentence wouldn't be the end of my point.

Student 5: Yeah so when we write our essays tomorrow, I'm gonna try to fit in a semi-colon in my thesis again.

Figure 2 illustrates my coding process and analysis of Text chunk \#49. 
Bracketed text\# 49 - ss Round 1:

Notes/ Jottings

- Peer obserrations on wkity - conventions duscussin - semi-colchs - "better"

Round 2:

Descriptive Codes

-using semi-coleons - persuasve skills

- peer edits - theuls statements

In Vivo Codes

- "make a point better" -make it better"

- "I'm gonna try it" - "malces $1+$ deeper"

\section{Round 3:}

Process Codes

- helpiny peers - teaching each oter understanding punctuatien rues - attemptiry to vse Pattern/ Category Codes

- teaching each otuer

- makirg writiry more effertive

Round 4:

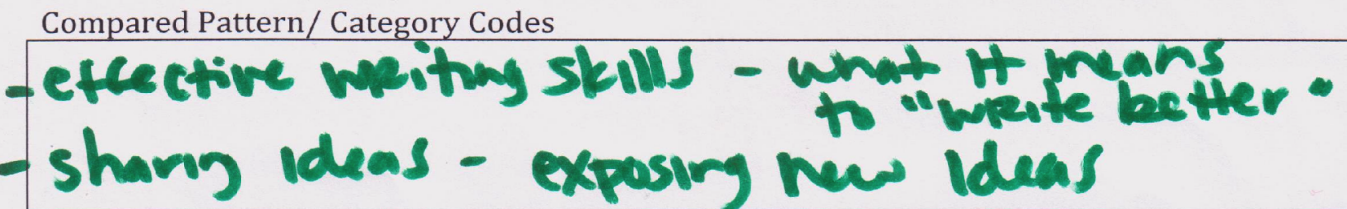

Themes

- Discussion can lead to understandiry new ideas. - sharing ideas can lead to effective writing
skilis.

Figure 2. Model analysis text chunk \#49. 


\section{Data Source \#2: Model Analysis 3}

The following is an excerpt from the transcript of Socratic questioning session \#3. It is 4.55 minutes into the discussion. This transcription is taking place during the literal level of questioning and moves into the inferential level of questioning. Students are discussing the creation, validity, and use of rubrics. The text chunk that I found important from this section is Text Chunk \#30.

\section{Socratic seminar text chunk \#30.}

Student 10: Well I've always been given the Oregon State rubric. The one with ideas and content and organization.

Student 9: And conventions. I hate that.

Student 1: Why do we have to learn about commas and write them all the time and use them all the time to get a good score

Student 10: Is that what everyone uses at all the schools?

Student 5: Yeah, I mean shouldn't all kids be judged by the same scale.

Student 1: Yeah, it depends what teacher you get.

Student 5: Who even came up with that rubric. Just all of a sudden they are like yeah let's grade on ideas and commas.

Facilitator: Well, having experience with different writing rubrics, what would you change? What would you add or take away from the rubric to assess your writing?

Student 9: I'd take out conventions. Who cares. Everyone knows how to use a period.

Student 6: Dude. Not everyone does.

Student 9: Okay so we can keep periods.

Student 10: Conventions are important. Remember that lesson we had when there were no periods or commas or anything. You can't read anything if there aren't any conventions. 
Student 4: I would add creativity

Student 9: That's kinda what ideas are right?

Student 4: Yeah but if I guess how do you grade creativity? How can you say one idea is more creative than another idea?

Student 6: I would keep organization, and ideas, and word choice. I would get rid of conventions. I would make it a pass or no pass for basic conventions. How can you say this person gets a exceeds in using periods and commas right and this person just gets a proficient in using periods and commas right. Isn't it just that you used them right or you didn't. How are there different levels?

Student 10: Who comes up with those levels? Do all teachers make their own rubrics?

Figure 3 illustrates my coding process and analysis of Text chunk \#30.

\section{Coding Model for Data Source \#3: Transcriptions From One-On-One Interviews}

My coding process after transcribing my interviews was similar to the coding process I used for the data collected from my Socratic questioning sessions. After transcribing the data, I began a pre-coding process where I put brackets around chunks of text and made initial notes. Next I began my second cycle of coding with Elemental Methods: Descriptive coding and In Vivo codes. Next, Process coding and Pattern codes would be the staple of my third cycle of coding. Then I was able to synthesize those codes into even more meaningful categories. This regrouping allowed me to create several categories and themes that eventually led me down a theoretical pathway. 
81

Bracketed text \# 30 - ss Round 1:

Notes/ Jottings

- Use of oregon state Rubric - unit, Assessment

Round 2:

Descriptive Codes

- categories used to assess waty-Rubric elements - tho and how Hubris are created

In Vive Codes

- "Ire always kenglien" - "Isthat what everyone uses"

" "who care up with twat" - "converters are important"

Round 3:

Process Codes

-discussing unity Rubrics - evalvaty assessment

-aralyng origins of pubs and unity traits

Pattern/ Category Codes

- Evaluator of writ Rubies

- discovery nu w ways to assess

Round 4:

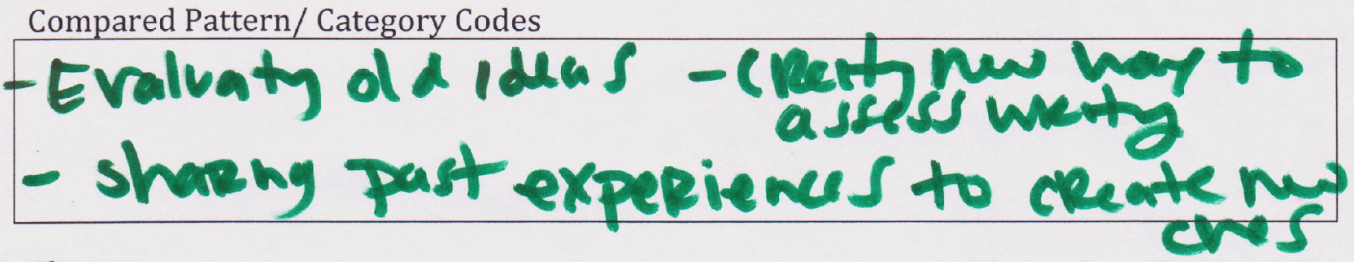

Themes

- Evalvatu can lead to create of murders - Discussing can lead to discovery.

Figure 3. Model analysis text chunk \#30. 
Again, analysis of my collected data was ongoing. Once I transcribed an interview, I would put the transcription through the process described above. Once I had more than one set of codes for each session, I compared the first set of data with the second. This comparison of categories established my fourth cycles of coding. This comparison informed the next data collection and so on. This helped me narrow down my categories and findings so that I could come up with a tentative theme. As the interviews carried on, I continued organizing, reorganizing, and refining my data into chunks, categories, and themes, and these understandings led me to a theory that would help me answer my research question.

\section{Data Source \#3: Model Analysis 1}

The following is an excerpt from the transcript of interview with Student \#4. The text chunk I found important to mark was text chunk \#32.

\section{Interview text chunk \#32.}

Facilitator: How do you think Socratic Seminars helped you?

Student: O.M.G. It was like we got to cheat. It was like we got to talk about the test before we took it. It was like I could take all their good ideas and copy them. Talking with my group helped me be a better writer.

Facilitator: How did "talking" with your group help you be a "better" writer?

Student: Well it wasn't just like a regular discussion. You know like you have in Social Studies. We had specific things to look at and specific things to talk about, and the point of everything wasn't a right or wrong answer. Usually in other classes you work with groups to come up with the right answer. In our Socratic group, we talked as a group to come up with the best answer. We talked about what we used to do and what each of us was doing. We talked about which one of us was more effective and then we taught each other how to do the effective thing that person was doing. So Socratic Seminars were good because, I guess, it's not like we were cheating. It's like we were studying.

Figure 4 illustrates my coding process and analysis of Text chunk \#32. 
Bracketed text \# $32-I$

Round 1:

Notes/ Jottings

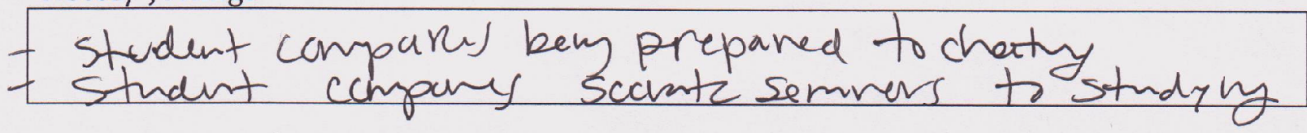

Round 2:

Descriptive Codes

- discussin companed tochenty - betterwarty - best answers instead of Rignt answer

In Vivo Codes -effecture Wraty skills

"I "could take tuir good ideas ard copy tem" " "he ped me ke

- "conne upwitr kest ansuer" "talled about " "favght

Round 3: "H's Ilke study exch oter"

Process Codes

- Compary ducussun to cheertytstudyy - talky teachy

- Comy up woth best ansver -studyz

Pattern/ Category Codes

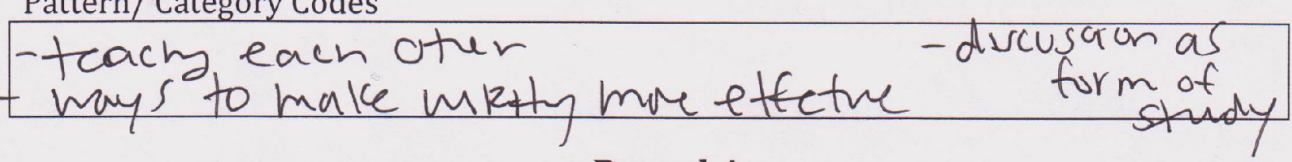

Round 4:

Compared Pattern/ Category Codes

- Discussin and teacly - menty "bette"
- Discursm is studyy -usy new skills

Themes

- Discussin can be used as a studyztool.

- Discussin can help studurts be tenclens.

- Evaluaty wirty stkills can lead to (Reaty) nur wart skills.

Figure 4. Model analysis text chunk \#32. 


\section{Data Source \#3: Model Analysis 2}

The following is an excerpt from the transcript of interview with Student \#3. The text chunk that I thought was important to note was Text Chunk \#22.

\section{Interview text chunk \#22.}

Facilitator: How can discussion about writing help improve a student's skills in writing?

Student: I feel like I learned a lot about how other people organize their ideas. Listening to other people's essays and what they put where. It was good to hear what other people do. All I ever really knew was a 5-paragraph essay and there's a hook and body paragraph and conclusion. It's like pretty much all they teach you here. It was really cool hearing what everyone does. Who knew there were different ways to do things? I've never really talked about ways to do things better. I always just try do the minimum asked of me and complete it on time. I never really try to do better or be better or write better. Teachers would give me feedback and honestly I would forget about it next period. These discussions were like the best feedback I ever got, because it was like the first time I wanted and knew how to do things differently in my writing and try to be more persuasive and try to be a better writer. It made me want to write more.

Figure 5 illustrates my coding process and analysis of Text chunk \#22.

\section{Overview of Major Findings}

After charting, transcribing, categorizing, analyzing, and coding all three data

sources, I was able to mark the similarities and discrepancies that existed between the

three sources. Thus, triangulation of my data provided a comprehensive insight that

helped verify and validate the findings from this study. It helped identify the inadequacies

found in one data source, minimize those inadequacies when the other two data sources

confirmed the same idea, and ultimately aided in my ability to draw several conclusions

that answered my research question. The findings from this study are divided into two

major conclusions. The first major finding is that Socratic questioning can help improve

the perceptions that students have about the writing process. The second major finding is 
85

Bracketed text \# 22 - I Round 1:

Notes/ Jottings

- Listening to others - Discussing as feedback

Round 2:

Descriptive Codes

- leaver new ways to unite - Motivator - feedback

In Vive Codes

- "A was good to hear what other people do" " "who kw te ere - "these discussions mere like the best fullback" were diftunt hays - "It made me want to write me" Round 3:

Process Codes
-lister to nu w doeas-shary experiences

- Receive feedback - Whity mane - dong te minium

Pattern/ Category Codes

- Collaborator - feedback -felly maturated

Round 4:

Compared Pattern/ Category Codes

- chary ideas and experiences
- Discussing as feedback
- Freely motivated by leary new concepts

Themes

- DIscussin can be used as a form of feedback - lustering and sharing can be motivatumal.

Figure 5. Model analysis text chunk \#22. 
that Socratic questioning can help improve the perceptions that students have about their own identities as writers.

\section{Major Finding \#1}

The first major finding from this study is that Socratic questioning can help improve the perceptions that students have about the writing process. All three data sources help verify this finding in different ways, and when juxtaposed, my analysis from each data source helps indicate how students changed. There is a distinct and positive change in the way that students experience the different aspects of the writing process after participating in Socratic questioning.

Data source \#2, the transcriptions from the Socratic questioning sessions, help verify that there was a distinct change in the way students experience the writing process. For example, the following In Vivo codes were highlighted from the beginning of the first discussion: "I was always taught" and "Wish I had my notes from last year." These In Vivo codes would not help answer my research question, if they were analyzed by themselves and separately. However, if you compare those In Vivo codes to the following In Vivo codes highlighted at the end of the discussion, one can begin to recognize a change: "I like what ___ did here, I would do that," "What if we did it this way," "Do you think it's persuasive if I put my counter claim paragraph first?"

The first set of codes is definite and in rooted in the past. Students do not seem to have a route for an answer and revert only to things they had previously learned. In addition, students are looking only to their own memories and their own experiences as a resource. In the second set of codes, students are opening up the discussion for other 
possibilities. They are looking to their peers for discovery and evaluation. They are assessing different options in hopes of a new creation. Here, I would claim that there is a change in the way that students perceive the writing process. I would argue that where they once felt alone, stuck, and without direction, participating in Socratic questioning helped them recognize that their peers, shared experiences, and collaboration can be a new way to approach what and how they write. Thus, this data source not only helped demonstrate how students perceive the writing process, it also helped illustrate the change in perception that students had after participating in Socratic questioning.

My analysis of my other data sources also led me to identify how students changed and how they changed their perceptions of the writing process. Data source \#1, the Reflection Surveys, shows that after participating in Socratic questioning sessions, students could identify tools to use when they brainstorm, write, and edit their writing. Before the study, students could not identify tools to help themselves write more effectively, they could not identify tools to help themselves fight writer's block, and they did not know how discussion could be beneficial to their next writing experience. After the study, students said that they could "talk to their peers" to figure out how to organize their writing. They said they would "listen to their groups to compare different ways" of organizing their writing to see which one "best fit" with what they needed to write. They also stated that "sharing and listening" to their peers was a "new and good" way to prepare for a writing assessment in class. Thus, students changed the way that they viewed the writing process and could now use and identify new and effective ways to write. 
Another interesting finding from data source \#1 was that students now found writing to be an easier task. The change between the pre and post surveys proved that after participating in Socratic questioning, students were not scared of the writing process, and they discovered new ways to share, listen, and use their peers to develop more effective writing skills. After the study, students understood how discussion with their peers could be a resource for their skills. For example, students shared: "It's easier now," "I feel like I know what to do," "I actually like to write now," and "We are always told not to talk to people in class. If only teachers would let us talk more.”

Additionally, findings from data source \#3, the interviews, also helped clarify how students experienced the writing process after being part of Socratic questioning. It was not until the interviews that students were able to put into words how discussion, Socratic questioning, and peer engagement helped them. For example, some of the categories that emerged after a few comparisons between interview data sets were: discussion leads to discovery, discussion is a feedback tool, Socratic questions promote collaboration, and dialogue can create change. I came to these conclusive categories via In Vivo quotes like: "talking helped me see a new side to writing," "listening to everyone else's ideas made me realize what I could do better," and “when you would ask us 'why' and 'how things could be different in the future', it made me think back to all the rubrics I had been given in the past. Just being pushed to answer the question why made me see where I could improve. It was the best feedback I could have been giving on my essay." A series of these types of In Vivo codes led to me to the comprehensive notion that 
Socratic questioning can improve the perception that students have about writing and the writing process.

\section{Major Finding \#2}

The second major finding from this study is that Socratic questioning can help improve the perception that students have about their own identities as writers. All three data sources help verify this finding in different ways. However, when compared and analyzed together, the three data sources help indicate how students felt about themselves as writers before the study, during the study, and after the study. There is a distinct and positive change in their perception of themselves as writers.

Data source \#1, the Reflection Surveys, help verify this finding. For example, as I compared the change between pre and post responses from all 10 students, it became increasingly clear that participation in Socratic questioning sessions played an important role in how students' perception of their own identities as writers changed. There was a distinct change in how students saw themselves. Before the study, students saw themselves as bad writers, who "sucked" at writing and "never knew what to do." At the end of the study, students saw themselves as effective and good writers, who could now write better.

Another interesting finding from this data source was the way that students drew a writer before and after the study. Before the study, students drew nondescript and past writers as stick figures. After the study, students spent more time and effort in drawing themselves as rounded figures with clothes and detail. Instead of drawing stick figures of famous writers from the past, they drew themselves as rounded figures with clothes and 
detail. This leads me to believe that students believe writing to be something that they can attain for themselves; it is not just for "Fitzgerald" and "Whitman." Thus, being a writer is not as distant and intangible as it once was. Drawing their own selves with clothes and details also led me to believe that students were paying more attention to the identity of their drawings, and in turn, they were paying more attention their own identity as writers.

Findings from my second and third data sources were not as cut and dried as those in the pre and post surveys. As I began to run the bracketed text chunks through my first few cycles of coding, I felt disappointed in the initial results. Not all chunks of text proved to be valuable sources that would help answer my research question. It was difficult to make connections. It was difficult to see how these dissected and deconstructed descriptions were ever going to create a cohesive idea. The first few chunks of coding were distinct and seemingly unrelated. I began to doubt my coding process, my analysis, and my research question. However, as I continued to code more chunks of text, it became increasingly clear that comparing the data after the third round of coding, was going to provide the most useful information. Ultimately, the first few rounds of coding, although crucial to maintaining participant voice and description, did not provide sufficient results when analyzed on their own. It was not until I had enough data to begin comparing patterns, categories, and In Vivo codes, that I was able to recognize how the patterns and categories were connected. The synthesis of the separate sets of data was the key to creating a theoretical path. Therefore, the third round of coding forced me to compare one set of collected data with the next, and this was where I 
was able to draw out themes and possible theories that would help answer my research question.

Ultimately, data source \#2, the transcripts from the Socratic questioning sessions, also demonstrated how students' perception of their own identities as writers had changed. For example, after many rounds of coding and many rounds of comparing patterns, I was able to conclude that in the beginning of the unit, students saw themselves as struggling students who did not do well in English and could never get a good score on their essays. Initially students did not even recognize themselves as writers. As the Socratic questioning sessions continued, students began to refer to themselves as writers. They began to discuss how practicing writing meant that they were writers. In fact, one student said, "I am on the football team. I practice football every day. On weekends, I am not just playing football, I am a football player. So wouldn't that be the same with writing? I am writing every day. On weekends, I am not just doing writing assignments, I am a writer." This single quote was one of the most meaningful quotes from my entire coding process. I kept coming back to it. It was profoundly accurate. This quote exemplifies how talking about writing, thinking about writing, sharing about writing, and evaluating writing helped the student recognize that he was doing more than just getting his work done. His perception of his own identity had changed. He had become a writer.

In addition, data source \#2 highlighted that students thought writing and rewriting was accessible, fun, and worthwhile. They believed that going back to edit one's writing was crucial to persuasive writing skills. They believed that writing more often and reading their peers' work more often would help them become effective writers. They 
were motivated by the engagement of their peers, they were motivated to write more often and more effectively, and they were motivated to help each other.

The findings from data source \#3, the interviews, were some of the most fundamental to developing this major conclusion. Even though I ran the interview text chunks through the same coding process that I used for coding the Socratic questioning sessions, the data derived from the interviews was different. The fact that the interviews were held at the end of the unit made it easier for students to take a metacognitive approach to the interviews. They were able to digest the unit of instruction, reflect on their experience, and provide thoughtful responses to the questions in the interview.

For example, the In Vivo codes found in the transcripts of the interviews helped me verify the finding that student perceptions of their own identities as writers had a positive change after they participated in Socratic questioning. The following quote is from taken from the interview with Student 6:

Do I think I have changed as a writer? Well . . yes. I feel better when I write. I am more confident in myself. I know now that writing is a process, which in turn, makes being a writer easier. You know? The whole notion of writing is that where you start is not really where you end up. So yeah . . I can write something that is total crap, but I go back and think about it and talk about it and change it to be better. So yeah ... I am a better writer. Before all this and before this unit, I really just thought I sucked at English and sucked at writing. I guess I see it more like a skill than a yes or no answer now. I feel like I will always be making myself a better writer. Maybe no one is a good writer . . . or you know . . . you can't really say that you are ... because we are always changing and getting better.

This quote not only fascinates me, but it plays an integral role in answering my research question. As you can hear throughout, this student is processing what has happened, what is being asked, and how they see themselves as a writer. Having participated in Socratic questioning, the student is now aware that being a good writer is 
not a definite state of being. They know now that one can change after discussion and metacognitive thinking. They know now that they will always be changing as a writer and that being a bad writer is simply temporary. Engaging in these types of discussions and participating in the writing process is what can help make someone be a better writer. This student once thought of themselves as "bad at English" and "bad at writing." Now, they are more confident and understand that writing is a skill that can always be improved, thus believing that they are in fact a good writer. 


\section{CHAPTER FIVE \\ CONCLUSIONS, IMPLICATIONS, AND FURTHER RESEARCH Summary and Conclusions}

As we enter into the information era, it is more important than ever to support students in becoming better writers. Federal and state educational agencies have increased expectations for students and teachers, and they have mandated new laws that emphasize the need for more effective ways to support student writing skills (NAGB, 2013; Oregon Department of Education, 2012). Ultimately, student achievement and performance in writing is a vital part of a student's success in and out of school, and we need to find ways to help students become better writers.

In the Socratic Method of education, teachers ask open-ended questions that are engaging and ultimately lead to discussion and a deeper analysis and inquiry of a topic or idea. These questions lead students to examine their own values, principles, understandings, assumptions, and beliefs (Elder \& Paul, 1998; Warren, 1994). The questions that are asked of the students enhance thinking and cognitive skills, and challenge students to ask their own questions, promoting even future comprehension and thinking skills. Both the open-ended questions and the responses from the students allow them to be actively involved in their education while taking ownership of the things they have learned. Some researchers find that this mode of questioning is the most powerful teaching approach that allows students to construct their own knowledge (Elder \& Paul, 1998; Warren, 1994). Socratic questioning is used to examine previous understandings, 
helps construct new assumptions, and fosters discussion and critical thinking skills (Maiorana, 1991; Paul, 1993).

The purpose of this study was to investigate if Socratic questioning is an effective tool for improving student perceptions of the writing process. The major aim of this study was to understand what methods or strategies improve students' perceptions of writing and the writing process. Thus, one research question was posed to accomplish this purpose: How can Socratic questioning improve students' perceptions of writing and the writing process?

Three data sources were used to answer this research question: transcriptions of audio-recordings from six Socratic questioning sessions that focused on persuasive writing techniques, transcriptions of audio-recordings from interviews with each of the 10 student participants after they participated in the Socratic questioning sessions, and the Reflection Surveys. Analysis, triangulation, and findings from these three data sources led me to several conclusions.

Ultimately, this study helps illustrate how Socratic questioning can positively impact the way students perceive themselves as writers. After the study, students found that being an effective writer was possible and that looking to peers for discussion and help was valuable. They believed that effective writing was attainable and that evaluation of one's writing techniques was a vital part of becoming a better writer. Most importantly, after participating in this study, students believed themselves to be writers. These students felt that being a writer was attainable and that becoming a writer meant engaging in the process of writing consistently and improving one's skills in the process. 
After participating in a series of writing-based Socratic questioning sessions, students also changed the way they perceive the writing process. They found that writing and rewriting was accessible, fun, and worthwhile. They believed that going back to edit one's writing was crucial to persuasive writing skills. They believed that writing more often and reading their peers' work more often would help them become effective writers. They were motivated by the engagement of their peers, they were motivated to write more often and more effectively, and they were motivated to help each other.

Eventually, the analysis of my findings led me to the following conclusions: Socratic questioning and discussion about writing allows students to engage, interact, analyze, debate, evaluate, and persuade each other. Participation in these types of discussions and these types of questions leads to change, discovery, motivation, and eventually a strengthening of skills. In conclusion, by addressing Socratic questions, students were able to positively improve their perception of the writing process and their own identities as writers.

\section{Discussion}

It is almost impossible to isolate the effects of a single method of instruction when considering academic achievement in a high school classroom. One cannot simply argue that a single specific method of instruction can impact student achievement. The truth is that in a classroom of 35 students, there will be 35 home lives to consider, 35 past experiences in that content area, 35 different learning styles, 35 eating habits, sleeping habits, coping skills, etc. There are too many factors in a student's life to positively and without a doubt argue that a single teaching method can boost achievement for all 
students. Isolating a method of instruction to demonstrate an effect is virtually impossible. However, if this is a valuable assumption, then how can we ever know what works and what does not work in the classroom?

The debate between the values of quantitative and qualitative methods is worth noting when considering this study. Although a quantitative study might show explicit growth in student improvement and achievement, this qualitative study was able to address the beliefs and perceptions of the participants. Ultimately, numbers cannot truly be the only aspect of research that is considered meaningful in the field of education. The beliefs, discoveries, changes, and perceptions of research participants hold exceptional value and are worth consideration. Thus, it is worth discussion. When considering student behavior, interaction, and achievement, is quantitative research more widely accepted in the field of education?

\section{Limitations}

As a researcher, I faced many challenges in conducting a qualitative study, and I need to be able to refer to and address the credibility of the descriptions, explanations, and interpretations that I am presenting in my study. Although addressing the concept of trustworthiness does not require adhering to the philosophy of an objective truth, it does require a researcher to address the ways in which they might be wrong; it requires a researcher to call out the rival hypotheses that might exist about their study (Maxwell, 2005). As a component of my research design, I use this section to address researcher bias and other limitations to my study. 
When addressing researcher integrity, researcher bias needs to be addressed. I am currently a high school teacher working with students, and I consistently use Socratic questioning in my own classroom as an instructional tool for writing. This is a definite bias that I hold, since my study is about high school students and the Socratic Method. To deal with this bias, I asked open-ended questions during all one-on-one interviews as well. Open-ended questions can eliminate my guidance in participant answers; participants can create their own path to answering interview questions. I also asked process and experience questions during all one-on-one interviews as well as during the six sessions. This allowed participants to tell their own story without my bias tainting their perspective.

Ethical limitations may arise when a teacher is the researcher. Students might feel unsafe, feel obligated to answer a certain way, or try to impress their teacher with exaggerated responses. In order to address these concerns, I conducted intimate and indepth interviews about the process of writing with students. I assessed how students perceived their own writing process and how Socratic questioning has played a role in their success as writers. By using my own students, I was able to take advantage of the close bonds and strong relationships that are already in place. As their teacher, I have been able to cultivate positive and respectful relationships with my own students, so they are already comfortable talking and sharing with me. Secondly, I did not ask student participants to assess me as a teacher, so there are no moral or ethical concerns. They were not be obligated to speak on behalf of my teaching skills or pressured to have the right answer. Rather, I asked students to reflect on their own skills. Lastly, I asked 
students to discuss and reflect on positive aspects of their own skills, which is always less intimidating than to speak about one's weaknesses.

Another important factor to address when considering teacher as researcher is that the teacher is also the facilitator for the Socratic questioning sessions. During Socratic sessions, facilitators should adhere to a specific protocol. Since I was the facilitator in my own classroom, it is necessary to note that use of my own protocol during Socratic questioning can be a limitation to this study. My protocol for using Socratic questioning requires the facilitator to stick to three types of questions when conducting a discussion. The first level of questions should be literal: questions based on facts. This will lead to the second level of questions that should be Inferential: questions that help apply meaning and interpretation to the facts. Finally, the last set of questions should be Evaluative: questions that address why those inferential understandings and meanings are important and how they connect to future facts and understandings.

Another limitation to this study is that it requires students to be honest about their own education and learning styles. It also requires students to be metacognitively aware. During the study, students were asked to reflect on their past, their present, and their futures. Students were pushed to analyze their own actions and behaviors. They were asked to use past experiences to develop new assumptions and behaviors. This task is a valid limitation because it requires a certain level of maturity from a student and a certain level of acknowledgment about their own lives.

Another limitation to this study is the selection of student participants. In order to purposefully select a small sample of 10 students, I eliminated possible student 
participants who have language or learning disabilities. I did not want to include students with any kind of learning or language disability, so this excludes any student who is Special Education, early ELL, had a language related IEP, or has a speaking 504 plan. Students on a modified diploma are given individualized work and do not complete the same assignments as a student who is on a regular graduation diploma. These students also receive a different modified diploma. Students in our early ELL program are categorized as being in the country less than 14 months. Some of these students speak and understand very little English. Excluding students with learning or language disabilities creates bias and is a major limitation. However, it allowed me to uncover truths about my topic that might otherwise be hindered or blocked by a student's ability to speak, discuss, contribute, or be able to understand the questions that were asked during Socratic questioning. However, this is a true limitation to the study, because I did not include all students with all learning abilities.

Power relationships within the classroom are another limitation to this study. For example, boys are generally more outspoken than girls, and thus might be more vocal during discussions. Another power relationship that is overlooked, but can be equally as invasive in a group discussion setting, is the relationship between "popular" and "unpopular" students. One way to address these power relationships in the classroom is to build community and a safe learning environment. Although there is no real way to eliminate power relationships completely, I believe investing in the time to include community-building activities is a good start. Taking the time to include communitybuilding activities can be very beneficial in breaking down power relationships. 
One last limitation is the fact that all Socratic questioning sessions were audiotaped. All students were aware of this audiotaping, and this could have interfered and changed the way that they discussed and interacted with each other. However, I believe that audiotaping is much less of an influence on students than videotaping, because during videotaping, students will be much more aware that their behavior will be caught on tape, but I still believe awareness of audiotaping can be a limitation.

\section{Implications}

Although the findings of this study were specific to student perceptions of their writing and the writing process, assumptions can be made about Socratic questioning and its broader implications on education; the findings from this study have practical implications for all teachers. Socratic questioning requires students to share stories about their life, their learning styles, and their past experiences. It also requires students to examine their assumptions, beliefs, knowledge, and new understandings. Essentially, this process allows them to reflect on their education and use it to better their skills.

Therefore, teachers can use this type of questioning and discussion is all subject areas to support their curriculum. Students in this study stated that Socratic questioning was an effective tool for instruction, feedback, and study. Through focused discussion with their peers, the foundation of past instruction became more clear, the implementation of current assessment strategies were explained, effective writing strategies were assessed, the use of current writing instruction was evaluated, and most importantly, students were talking about writing. Thus, teachers should use Socratic questioning as a means for further discussion and discovery in all content areas. Even though some teachers might 
argue that instructional time should be used for instruction, and that metacognitive talking about one's content might not be the best use of that time, there are hidden and worthwhile benefits to providing students the space and time to engage in these types of discussions.

This study also presents broader social implications. If students participate in Socratic questioning, they will consistently be working with peers to create new and effective ideas. This process is the basis of a democratic society. Assuming that teachers do not provide direct answers, Socratic questioning stimulates students' minds and requires them to engage in dialogue and self-reflection. Despite the necessity for a focused topic of discussion, the simple act of working in a group to assess and evaluate means students are collaborating, communicating, bonding with peers, and developing ideas that can be widely accepted and appreciated. Through the use of Socratic questioning, students are inevitably forced to be responsible for examining their own ethics, assumptions, and values as well as to be able to share those ideas with their peers. The Socratic Method is a critical and demanding line of inquiry. It puts the world up to the light for examination, asks students what they think, and emphasizes the importance of accountability and insights. The use of Socratic questioning in the classroom can be beneficial to all students. If it is used to discuss, analyze, and generate ideas, then the tenets of a democratic society can be implemented in one's own classroom.

\section{Future Research}

The findings from this study indicate that Socratic questioning can improve the perception of writing and the writing process. However, there are many questions that 
arise after considering these findings which warrant further study. How can Socratic questioning impact students in younger grade levels and other content areas? Can a qualitative study on a larger scale highlight more explicit findings? Can the effects of this type of reflective questioning be measured quantitatively? A quantitative study might be able to show growth in student writing, if measured before and after participation in Socratic seminars. A longitudinal qualitative study with control groups could provide valuable and measureable findings about Socratic questioning. Further study in this area is warranted, and it could be essential to finding more effective instructional techniques teachers can implement in their classrooms to support student writing. 


\section{REFERENCES}

Achieve, Inc. (2011). Closing the expectations gap 2011: Annual 50-state progress report on alignment of high school policies with the demands of college and work. Washington, DC: Achieve Inc.

Bandura, A. (1986). Social foundations of thought and action. Englewood Cliffs, NJ: Prentice-Hall.

Black, S. (2001). Ask me a question: How teachers use inquiry in the classroom. American School Board, 188(5), 43-45.

Bloom, B. S. (Ed.). (1956). A taxonomy of educational objectives, handbook 1: The cognitive domain. New York, NY: Longman.

Boghossian, P. (2006). Socratic pedagogy, critical thinking, and inmate education. Journal of Correctional Education, 57(1), 42-63.

Brand, A. G. (1980). Creative writing in English education: An historical perspective. Journal of Education, 162(4), 63-81.

Brooks-Gunn, J., \& Duncan, G. J. (1997). The effects of poverty on children. Children and Poverty, 7(2), 55-71.

Brown, J. S., Collins, A., \& Duguid, P. (1989). Situated cognition and the culture of learning. Educational Researcher, 18(1), 32-42.

Carnevale, D. (2005). Holding a Socratic chat: A quantitative study. Chronicle of Higher Education, 51(42), 44-78.

Carroll, J. A., \& Wilson, E. E. (1993). Acts of teaching: How to teach writing. Englewood, CA: Libraries Unlimited.

Cotton, K. (1989). Classroom questioning: Close-up no. 5. Portland, OR: Northwest Regional Educational Laboratory.

Croasmun, J. (2010). The effects of an instructional method on adult learning: A qualitative study (Doctoral dissertation). Available from ProQuest Dissertations and Theses database. (UMI No. 9986765)

Elder, L., \& Paul, R. (1998). The role of Socratic questioning in thinking, teaching, and learning. Clearing House, 71, 297-301. 
Ennis, R. (1996). Critical thinking. Upper Saddle River, NJ: Prentice Hall.

Ernest, P. (1994). Varieties of constructivism: Their metaphors, epistemologies and pedagogical implications. Hiroshima Journal of Mathematics Education, 2, 1-14.

Fasko, D. (2003). Critical thinking: Origins, historical development, and future directions. Cresskill, NJ: Hampton Press.

Flowers, L., \& Hayes, J. R. (1981). A cognitive process theory of writing. College Composition and Communication, 32(4), 365-387.

Fosnot, C. T. (1996). Constructivism: Theory, perspectives, and practice. New York, NY: Teachers College Press.

Freire, P. (1984). Pedagogy of the oppressed. New York, NY: Continuum.

Gallas, K. (1998). Sometimes I can be anything: Power, gender, and identity in a primary classroom. New York, NY: Teachers College Press.

Garlikov, R. (2000). Logic and educational research. Educational Policy Analysis Archives, 8(53), 112-145.

Glaser, E. (1941). An experiment in the development of critical thinking. New York, NY: Columbia University, Teachers College.

Graham, S., \& Perin, D. (2007). Writing next: Effective strategies to improve writing of adolescents in middle and high schools. Washington, DC: Alliance for Excellence in Education.

Harrop, A., \& Swinson, J. (2003). Teachers' questions in the infant, junior and secondary school, Educational Studies, 29(1), 49-57.

Himley, M. (1997). Political movements in the classroom. Portsmouth, NH: Heinemann Cook.

Hull, G., \& Rose, M. (1989). Rethinking remediation: Toward a social-cognitive understanding of problematic reading and writing. Written Communication, 6(2). Retrieved from http://wcx.sagepub.com/content/6/2/139.short

Ilaria, D. R. (2002, October 26-29). Questions that engage students in mathematical thinking. Proceedings of the $24^{\text {th }}$ annual meeting of the North American Chapter of the International Group for the Psychology of Mathematics Education (Vol. 14; SE 066 887), Athens, GA.

James, L., \& Unwin, L. (2013). Learning for the knowledge-based economy. Journal of Education and Work, 26, 243-266. 
Knapp, M. (1995, June). Academic challenge in high-poverty classrooms. Phi Delta Kappan, 76(10), 770-776.

Krathwohl, D. R. (2009). Methods of educational and social science research ( $3^{\text {rd }}$ ed.). Long Grove, IL: Waveland.

Maiorana, V. P. (1991). The road from rote to critical thinking. Community Review, 11, 53-63.

Manke, P. (1997). Classroom power relations: Understanding student-teacher interactions. Mahwah, NJ: Lawrence Erlbaum.

Marshall, C., \& Gerstl-Pepin, C. (2005). Re-framing educational politics for social justice. Boston MA: Pearson Education.

Martino, A. M., \& Maher, C. A. (1999). Teacher questioning to promote justification and generalization in mathematics: What research practice has taught us. Journal of Mathematical Behavior, 18(1), 53-78.

Marzano, R. J., Pickering, D. J., \& Pollock, J. E. (2001). Classroom instruction that works: Research-based strategies for increasing student achievement. Alexandria, VA: Association for Supervision and Curriculum Development.

Maxwell, J. A. (2005). Qualitative research design: An interactive approach $\left(2^{\text {nd }}\right.$ ed.). Thousand Oaks, CA: Sage.

Mee, M. (2000). A case of three seventh grade students' perceptions of the influence of Socratic seminar on their motivation for learning. Washington, DC: George Washington University Press.

Merriam, S. B. (2009). Qualitative research: A guide to design and implementation. San Francisco, CA: Jossey-Bass.

Mezirow, J. (2000). Learning to think like an adult: Core concepts of transformation theory. San Francisco, CA: Jossey-Bass.

Monaghan, E. J. (2005). Learning to read and write in colonial America. Boston, MA: University of Massachusetts Press.

Moore, L., \& Rudd, R. (2002). Using Socratic questioning in the classroom. Agricultural Education Magazine, 75(3), 57-87.

Moyer. S., \& Milewicz, E. (2002). Learning to question: Categories of questioning used by pre-service teachers during diagnostic mathematics interviews. Journal of Mathematics Teacher Education, 5, 293-315. 
Murphy, J. J. (Ed.). (1990). A short history of writing instruction from ancient Greece to twentieth century America. Davis, CA: Hermagoras Press.

Murray, D. (1972). Teach writing as a process not product. The Leaflet, 11(14), 3-16.

Myhill, D., \& Dunkin, F. (2002). What is a good question? Literacy Today, 33, 8.

National Academies. (2006). Rising above the gathering storm: Energizing and employing America for a brighter future. Washington, DC: National Academy Press.

National Assessment Governing Board. (2013). Achievement level reports and analysis: The nation's report card results. Retrieved October, 1, 2013, from http://www.nagb.org

National Council of Teachers of English. (2012). Standards for the English language arts: Writing. Newark, DE: International Reading Association.

National Governors Association. (2005). Reading to achieve: A governor's guide to adolescent literacy. Washington, DC: National Academy Press.

National Research Council. (2008). Inquiry and the national science education standards. Washington, DC: National Academy Press.

Oregon Department of Education. (2012). Get ready Oregon: Diploma requirements. Retrieved May, 6, 2012, from http://www.ode.state.or.us

Paul, R. W. (1993). Critical thinking: What every person needs to survive in a rapidly changing world. Santa Rosa, CA: Foundation for Critical Thinking.

Paul, R. W., \& Eder, L. (2007). Miniature guide for those who teach on how to improve student learning: 30 practical ideas. Dillon Beach, CA: Foundation for Critical Thinking.

Paul, R. W., Elder, L., \& Bartell, T. (1997). California teacher preparation for instruction in critical thinking: Research findings and policy recommendations. Sacramento, CA: California Commission on Teacher Credentialing.

Persky, H. R., Daane, M. C., \& Jin, Y. (2003). The nation's report card: Writing 2002 (NCES 2003-529). Washington, DC: U.S. Government Printing Office.

Phillips, D. C. (1990). Post-positivistic science: Myths and realities. In E. Guba (Ed.), The paradigm dialog (pp. 31-45), Newbury Park, CA: Sage.

Phillips, D. C. (1995). The good, the bad, and the ugly: The many faces of constructivism. Educational Researcher, 24(7), 5-12. 
Piaget, J. (1980). The psychogenesis of knowledge and its epistemological significance. In M. Piattelli-Palmarini (Ed.), Language and learning: The debate between Jean Piaget and Noam Chomsky (pp. 71-192). Cambridge, MA: Harvard University Press.

Plato. (1995). The republic. London, England: Penguin Books Ltd.

Popkewitz, T. S. (Ed.). (1987). The formation of school subjects: The struggle for creating an American institution. New York, NY: Falmer.

Raimes, A. (1991). Out of the woods: Emerging traditions in the teaching of writing. TESOL Quarterly, 25(3), 407-430.

Ramsey, S., Gabbard, C., Clawson, K., Lee, L., \& Henson, K. T. (1990). Questioning: An effective teaching method. Clearing House, 63, 420-422.

Rumberger, R. W., \& Palardy, G. (2005). Does segregation still matter? The impact of student composition on academic achievement in high school. Teachers College Record, 107(9), 1995-2045.

Sahin, A., \& Kulm, G. (2007). Sixth grade mathematics teachers' intentions and use of probing, guiding, and factual questions. Unpublished manuscript.

Saldana, J. (2009). The coding manual for qualitative researchers. Thousand Oaks, CA: Sage.

Schurr, S. (2000). How to improve discussion and questioning practices: Tools and techniques. Staff development kit \#2. Westerville, OH: National Middle School.

Shain, B. (1995). Thinking variants that emerge in a reading seminar based on a Socratic Method of questioning. Caldwell, NJ: Caldwell University Press.

Shaughnessey, M. P. (1977). Errors and expectations: A guide of the teacher of basic writing. New York, NY: Oxford University Press.

Skinner, B. F. (1987). Upon further reflection. Englewood Cliffs, NJ: Prentice-Hall.

Stevens, R. (1912). The question as a means of efficiency in instruction: A critical study of classroom practice. New York, NY: Columbia University, Teachers College.

United States Department of Education. (2012). NCLB policy: Elementary and secondary education. Retrieved June 19, 2012, from http://www.ed.gov/policy

Vygotsky, L. S. (1978). Mind in society. Cambridge, MA: Harvard University Press. 
Walsh, J., \& Sattes, B. (2011). Thinking through quality questions. Thousand Oaks, CA: Sage.

Walshe, R. D. (1981). Children want to write. Rozelle, Australia: Primary English Teaching Association.

Ward, I. (1994). Literacy, ideology, and dialogue: Towards a dialogic pedagogy. New York, NY: State University of New York Press.

Warren, T. H. (1994). Critical thinking beyond reasoning. In K. S. Walters (Ed.), Rethinking reason: New perspectives in critical thinking (pp. 221-231). Albany, NY: State University of New York Press.

White, D., Gunasekaran, A., \& Ariguzo, G. (2012). The structural components of a knowledge-based economy. International Journal of Business, Innovation, and Research, 25, 44-64.

Wiggins, G., \& McTighe, J. (2005). Understanding by design. Alexandria, VA: Association for Supervision and Curriculum Development.

Winne, P. H. (1979). Experiments relating teachers' use of higher cognitive questions to student achievement, Review of Educational Research, 49, 13-50. 
APPENDIX A

INFORMED PARENT PERMISSION LETTER 


\section{Parent Form \\ $12^{\text {th }}$ Grade Socratic Seminar Study}

Dear Parent or Guardian,

I am a doctoral student at Portland State University. I am conducting a research study on student writing and Socratic Seminars in 12th grade classrooms. I want to investigate if and how Socratic questioning helps students become better writers. I request permission for your child to participate.

All students in the class will be participating in six Socratic Seminar discussions, one reflection survey at the start of the unit, and one reflection survey at the end of the unit. The only difference between a student in the class and a student who is in the study is that a student in the study will take part in an interview after the unit is over. The study will be explained in terms that your child can understand, and your child will participate only if he or she is willing to do so. Only my faculty advisor at Portland State and I will have access to your child's information and participation data. At the conclusion of the study, children's responses will be reported as an analysis of Socratic Seminars and its impact on student writing. No names will be connected to any of the interview or discussion results. Your child's information and responses will be kept confidential.

Participation in this study is voluntary. Your decision whether or not to allow your child to participate will not affect the services normally provided to your child by the Centennial School District. Your child's participation in this study will not lead to the loss of any benefits to which he or she is otherwise entitled. Even if you give your permission for your child to participate, your child is free to choose not to participate. If your child agrees to participate, he or she is free to end participation at any time. Any information that is obtained in connection with this study will remain confidential. Confidentiality will be maintained by storing students' responses in a locked cabinet, and limiting data access to only myself. School, student, and teacher names will be changed when presenting this data to any other sources, and no student names will be published at any time.

Mandatory Reporting: The Portland State University Institutional Review Board (IRB) that oversees human subject research and/or other entities may be permitted to access records, and there may be times when we are required by law to share your information. It is the investigator's legal obligation to report child abuse, child neglect, elder abuse, harm to self or others or any life-threatening situation to the appropriate authorities, and; therefore, your confidentiality will not be maintained.

Researcher contact information: Should you have any questions, or desire further information, please email me at rana_houshmand@centennial.k12.or.us, or my advisor, Susan Lenski, at sjlenski@pdx.edu. You may also call me at 503-949-1138 or 503-762$6180 \times 5598$. 
PSU/IRB contact information: If you have questions regarding your rights as a research participant, you may call the PSU Office for Research Integrity at (503) 725-2227 or 1(877) 480-4400. The ORI is the office that supports the PSU Institutional Review Board (IRB). The IRB is a group of people from PSU and the community who provide independent oversight of safety and ethical issues related to research involving human participants. For more information, you may also access the IRB website at https://sites.google.com/a/pdx.edu/research/integrity.

If you would like your child to participate in this study, please read and fill out the bottom of this form. Please return this form to Rana Houshmand (Ms. Houshmand). A copy of the form you signed will be given to the parent and student. Either you or your child can return the form. If you would not like your child to participate in this study, there is no need to respond or fill out any forms.

Sincerely,

Rana Houshmand, Portland State University

Print name of Parent/Guardian:

Print name of student participant:

Signature of Parent/Guardian:

Date: 
APPENDIX B

INFORMED ASSENT TO PARTICIPATE IN RESEARCH 


\section{Student Form \\ $12^{\text {th }}$ Grade Socratic Seminar Study}

1. My name is Rana Houshmand. I am a doctoral student at Portland State University.

2. I am asking you to take part in a research study because I am trying to learn more about improving student writing and the links to Socratic seminars. I am hoping to find out if Socratic seminars play a role in improving student writing. I want to learn if Socratic questioning helps you become a better writer.

3. Next week, our class will begin a persuasive writing unit. In this unit all students will be asked to participate in writing lessons, writing activities, and Socratic seminars. As a student in our classroom, you will be asked to participate in 6 Socratic seminars, one onehour interview, one reflection survey at the start of the unit, and one reflection survey at the end of the unit. If you want to be part of the study, the only difference between you and a student who does not want to be part of the study is that you will meet with me for an interview after the unit is over.

4. There are no known risks to participating in this study. Your involvement in this study will in no way negatively impact your grade in this class or your position as a student. This is a completely voluntary study and your participation in this study is not mandatory.

5. Even if your parent/guardian gives you permission to participate in this study, it is your decision to participate in this study or not.

7. If you do not want to be in this study, you do not have to participate. Remember, being in this study is up to you and no one will be upset if you do not want to participate. If you do choose to participate, you may change your mind at any time.

8. You can ask any questions that you have about the study. If you have a question later that you cannot think of now, I would be happy to answer it later.

9. Signing your name at the bottom means that understand all the above information and that you agree to be in this study.

*Mandatory Reporting: The Portland State University Institutional Review Board (IRB) that oversees human subject research and/or other entities may be permitted to access records, and there may be times when we are required by law to share your information. It is the investigator's legal obligation to report child abuse, child neglect, elder abuse, harm to self or others or any life-threatening situation to the appropriate authorities, and; therefore, your confidentiality will not be maintained. 
*Researcher contact information: Should you have any questions, or desire further information, please email me at rana houshmand@centennial.k12.or.us, or my advisor, Susan Lenski, at sjlenski@pdx.edu. You may also call me at 503-949-1138 or 503-762$6180 \times 5598$.

*PSU/IRB contact information: If you have questions regarding your rights as a research participant, you may call the PSU Office for Research Integrity at (503) 725-2227 or 1(877) 480-4400. The ORI is the office that supports the PSU Institutional Review Board (IRB). The IRB is a group of people from PSU and the community who provide independent oversight of safety and ethical issues related to research involving human participants. For more information, you may also access the IRB website at https://sites.google.com/a/pdx.edu/research/integrity.

If you would like to participate in this study, please read and fill out the bottom of this form. Please return this form to Rana Houshmand (Ms. Houshmand). A copy of the form you signed will be given to the parent and student. Either parent or student can return the form. If you would not like to participate in this study, there is no need to respond or fill out any forms.

Signature of Student Participant

Printed Name of Student Participant

Date 
APPENDIX C

REFLECTION SURVEY 


\section{Reflection Survey}

1. Do you feel you are a good writer? Why or why not?

2. What strategies have helped you become a better writer?

3. How do you think Socratic questioning helps you?

4. Do you think that Socratic questioning is a good tool for teachers to use when giving writing instruction? Why or why not?

5. At what point do you usually get stuck when you write?

6. What are your writing roadblocks?

7. What do you do when you get writer's block? Does that work for you?

8. Do you think your peers can help you become a better writer? How?

9. How can you help your peers become better writers?

10. In the box below, draw what you think a writer looks like, then below the box, write a few sentences to describe your writer. 
APPENDIX D

SAMPLE SOCRATIC QUESTIONS 


\section{Sample Socratic Questions}

\section{Literal:}

-What can you tell me about your writing?

-How did you develop your claims?

-How did you organize your essay?

-What types of punctuation did you use?

-What types of sentences did you use?

-How would this score on the rubric?

\section{Inferential:}

-Why did you organize your essay that way?

-Which one is more persuasive and why?

-Why did you use those types of punctuation and not others?

-What do you mean by "better" or "bad" writing?

-Why did it get that score on the rubric?

-Why are you/ are you not a confident writer?

Evaluative:

-Can you organize your essay in other ways? If so, what?

-What other kinds of punctuation could have been used in your writing and how?

-What other kinds of sentences could have been used in your writing and how?

-How could this piece of writing received a higher score on the rubric?

-How can you be more persuasive when you write?

-What can you do to be more confident when you write? 
APPENDIX E

SAMPLE INTERVIEW QUESTIONS 


\section{Sample Interview Questions}

What can you tell me about your writing?

In what areas do you feel like you have improved?

How did talking with your peers impact your writing?

Did you learn something from your peers during any of the six sessions?

What did you learn about writing or your own writing?

Tell a story about a time you felt like you had improved in your writing.

Describe some instructional tools your teachers have used for writing instruction.

Have those instructional tools been helpful and how?

How can discussion about writing help a student improve their skills in ideas and content, organization, and conventions?

How can Socratic questioning about writing help students?

Did Socratic questioning impact you as a writer? 